INSTITUTO DE PESQUISA ENERGÉTICAS E NUCLEARES - IPEN Autarquia Associada à Universidade de São Paulo

\title{
Parâmetros para produção de fontes de iodo-125 utilizadas em Braquiterapia
}

Carla Daruich de Souza

Tese apresentada como parte dos requisitos para obtenção do Grau de Doutor em Ciências na Área de Tecnologia Nuclear - Aplicações.

Orientadora:

Dra. Maria Elisa Chuery Martins Rostelato

São Paulo

2016 


\section{Dedicatória}

Dedico este trabalho

Às noites mal dormidas

às pessoas muito queridas que perdi às promessas que tentei concretizar

Muitas vezes eu

Não desisti mesmo com dúvidas

da força da família dependi e na querida "chefa" me apoiei

No passado aprendi a lição Do presente não desisti Como resultado espero ter ajudado Este é meu legado 


\section{Agradecimentos}

À minha querida orientadora e amiga, Dra Maria Elisa C.M. Rostelato.

À minha linda famíglia: Mamy (Janete), Daddy (Emerson) e Cabelo (Caio).

Aos amigos do grupo de braquiterapia do IPEN: Dr. Carlos Zeituni, Dr. Anselmo Feher, Dr. Osvaldo Costa, Dr. Rodrigo Crespo Mosca, Dr. Eduardo Moura, mSc Daiane C. Barbosa de Souza , mSc Bia Ribeiro Nogueira, mSc Bruna T. Rodrigues, mSc Rodrigo Tiezzi, mSc Fábio de Mattos, mSc Marcos Benega e, em especial, Dr. João “Jonhyyyyy" Moura e o quase Dr. Fernando "Fêfê" Peleias Jr.

Aos amigos do IPEN: Mara de Melo Munhoz, mSc Clécia Sousa, mSc Diego Vergaças, Dr. Jõao Trencher, mSc. Letícia Mesquita, Dra. Maria da Conceição Pereira, Dra. Yasko Kodama, Dra. Luci B. Machado, Dr. Leonardo A. e Silva, Dr. Roberto Frandlich, Dr. Roberto Vicente, Dr. Carlos Mesquita, Dra. Margarida Hamada e, em especial, ao meu querido amigo Laércio Carvalho.

Aos amigos e colegas do Instituto de Química: Dr. Koiti Araki e Roberta Mansini.

Aos amigos da Universidade de Laval: Mitra Zarifi, Dimitria Camasão, Clayton Campelo, Carolina Bortolan, Jad Mousselli, Stéphane Turgeon, Pascale Chevallier e Dr. Marc-André Fortin pelo carinho e parceria.

Aos amigos da Washington State University: Thomas Hayes, Mirissa Smith (mimimimi), Emily Witthuhn, Shalina Borttoff, Brianda Lopes, Ashton Powell, Winston Slocumb, Patrice Lion e, em especial, ao Dr. Paul Benny e família.

Aos amigos da Academia Overall em especial Carla Cucolo, Cibele Menezes e aos professores Ricardo Augusto, Leandro Santos, Tita Alcantara, André Lastella, Luciana Paes e Priscila Pinto. 
Aos queridos David Kubiatowicz e Dra. Izabela Cieszykowska.

Aos amigos quebecois Fernanda Camara e Fabrício Feijó

Para Ivone Boschini e meus queridos alunos Iris Boschini, Giulia Dallari, Pedro Meneses e Lucas Armonia.

Para minhas eternas vizinhas Tamara Alvarenga e Ana Clara Marton.

Para as brasileiras lindas da WSU Micheli Horbach, Carolina Filardi, Ana Paula Oliveira, Maria Clara Cardieri, Letícia Fanucchi e Joaquim "Joca” Marques (o menino entre as meninas).

À CAPES pela confiança e pela oportunidade concedida na bolsa sanduíche.

Ao IPEN, que sempre me apoiou desde a iniciação científica. 
"O que sabemos é uma gota; o que ignoramos é um oceano."

Estamos enganados se achamos que somos "doutores" em um assunto Isaac Newton, completado por Carla Daruich de Souza 


\title{
Parâmetros para produção de fontes de iodo-125 utilizadas em Braquiterapia
}

\author{
Carla Daruich de Souza
}

RESUMO

Como o diagnóstico do cancer de próstata está cada vez mais eficiente e cânceres em pacientes cada vez mais jovens estão sendo descobertos, a necessidade de desenvolvimento de tratamentos que provoquem menores efeitos colaterais é muito grande. Além disso, tratamentos rápidos, com pouca dor e eficientes são de extremo interesse também para os pacientes com idade avançada. Com a finalidade de diminuir custos e disponibilizar o tratamento para mais homens, o IPEN está construindo um laboratório para a fabricação de fontes radioativas para o tratamento braquiterápico. Essas fontes são inseridas diretamente dentro do câncer e utilizam a radiação do iodo-125 para destruir o tumor. Como a reprodução de técnicas existentes seriam custosas, novos métodos para fixação do lodo-125 no núcleo de prata dessa semente devem ser desenvolvidas. Este trabalho apresenta dois métodos inéditos. O primeiro, desenvolvido em parceria com o Instituto de Química da USP, utilizou a solução piranha para decapar a superfície e o nitrato de ferro III para remover um elétron da prata metálica. O iodo-125 adere na superfíce com 37,76\% de eficiência. No segundo métodos três variações foram apresentadas inspiradas em conceitos utilizados por joalheiros: núcleos de prata escurecidos pelo talco comum, núcleos escurecidos com prata e tiossulfato de sódio e núcleos escurecidos somente com tiossulfato de sódio. Os resultados foram 19,17\%, 53,39\% e 71,70\% de eficiência, respectivamente. Outros aspectos da reação foram discutidos: $\mathrm{pH}$ da reação, frasco utilizado no experimento, presença de luz, técnicas de medição, volume da reação, segurança e pureza química. As modificações na superfície foram visualizadas por MEV e analizadas por EDX. Como resultado, uma nova metodologia para produção de sementes de iodo-125 foi desenvolvida e analisada. 


\title{
Parameters for the production of iodine-125 sources used for brachytherapy
}

\author{
Carla Daruich de Souza
}

\begin{abstract}
As the diagnosis of prostate cancer is becoming more efficient and cancers are being discovered in younger patients, the need to develop treatments that cause fewer side effects is huge. Also, fast and efficient treatments with little pain are of extreme interest also for patients with advanced age. In order to reduce costs and provide treatment for more Brazilian men, IPEN is building a laboratory for the manufacture of radioactive sources for brachytherapy treatment. These sources are inserted directly inside the cancer and use the radiation from iodine-125 to destroy it. Since reproducing existing techniques would be costly, new methodologies for fixating the $\mathrm{I}^{125}$ onto silver core of this seed should be developed. This thesis presents two new methodologies. The first, developed in partnership with the USP Chemistry Institute, used the piranha solution to remove the oxide from the surface and iron III nitrate as oxidizing agent for silver. The iodine-125 is then reacts with the silver yielding in $37.76 \%$ efficiency. In the second methodology three variations were presented inspired by concepts used by jewelers: silver nuclei darkened by common talc, darkened nuclei with silver and sodium thiosulfate and darkened nuclei achieved only with sodium thiosulfate. The yield results were $19.17 \%, 53.39 \%$ and $71.70 \%$, respectively. Other aspects of the reaction were discussed: $\mathrm{pH}$, type of reaction flask, the presence of light, measurement techniques, the reaction volume, safety and chemical purity. Surface modifications were visualized by SEM and characterized by EDX. As a result, a new methodology for producing the iodine-125 brachytherapy seeds were developed.
\end{abstract}




\section{Sumário}

1. INTRODUÇÃO

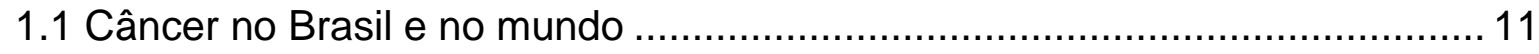

1.2 Braquiterapia e as sementes de iodo-125 ............................................ 12

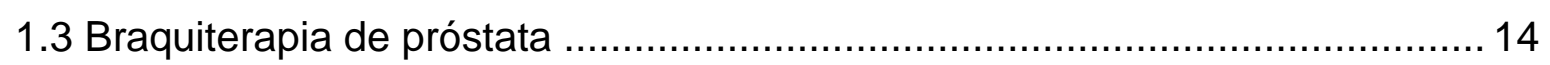

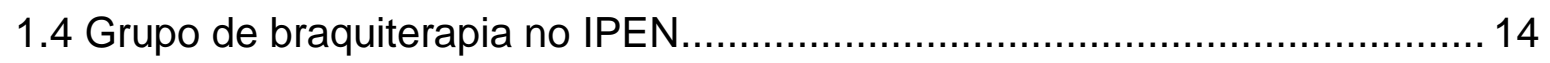

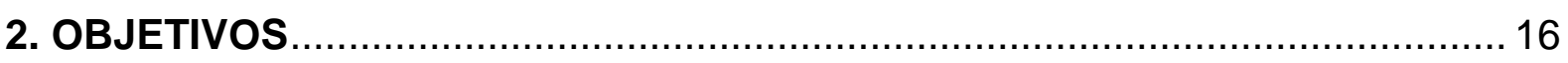

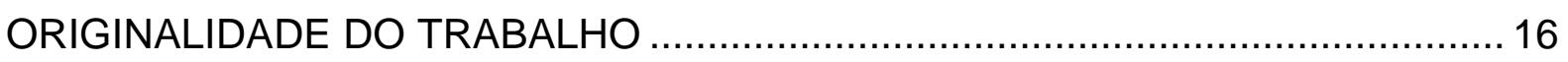

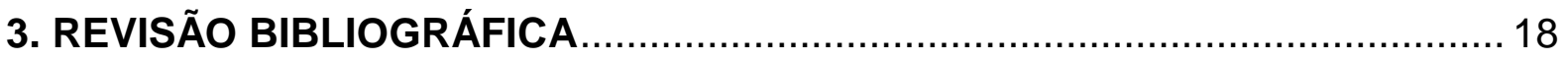

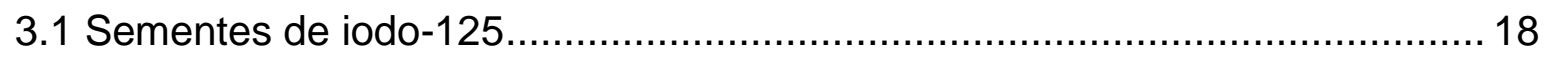

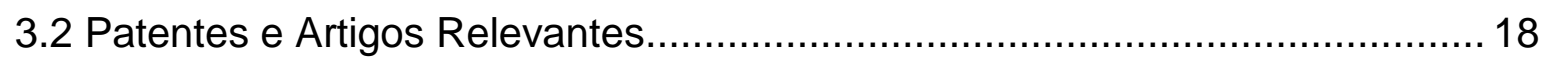

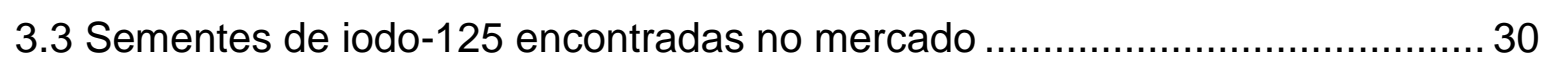

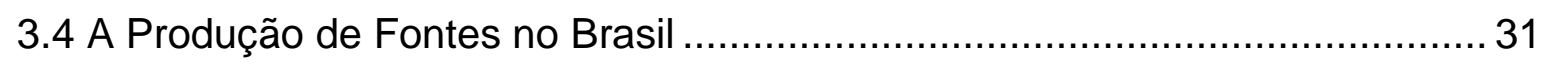

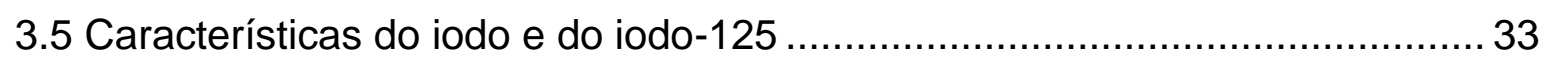

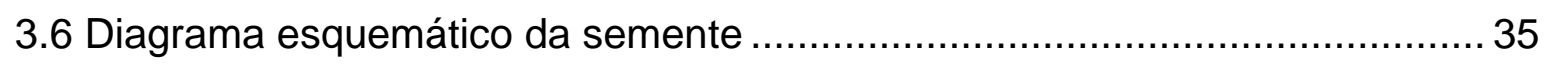

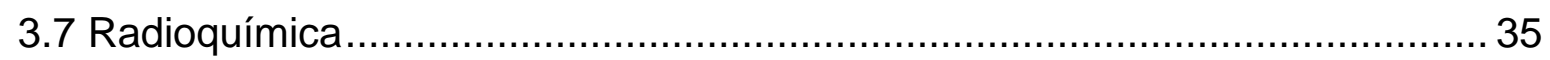

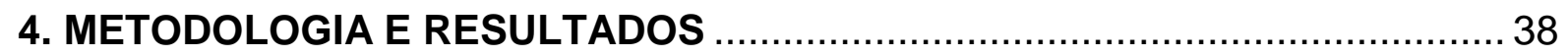

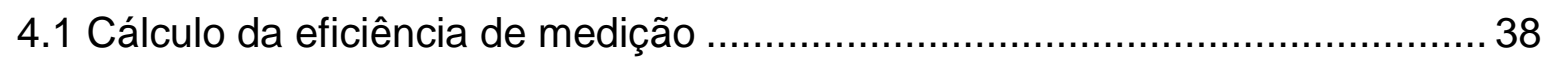

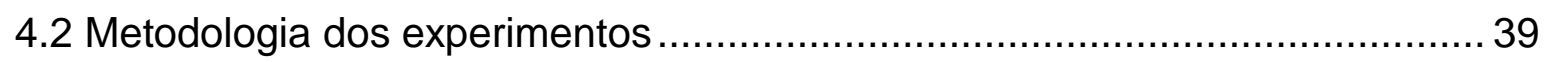

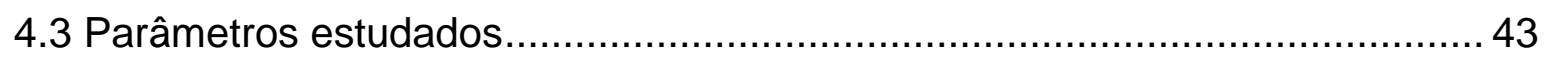

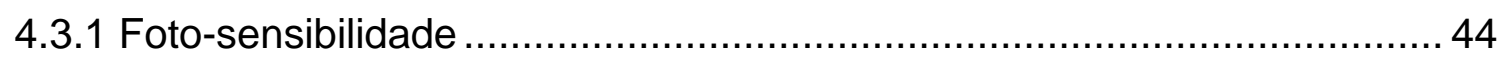

4.3.2 "O iodo-131 tem o mesmo comportamento do iodo-125"......................... 44

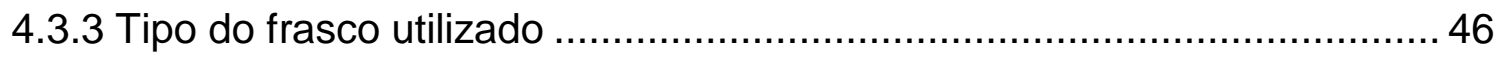

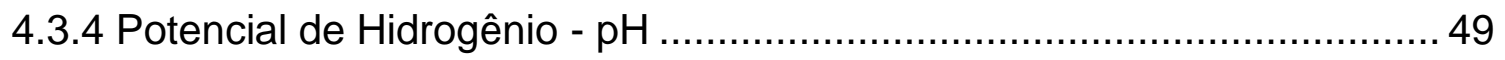

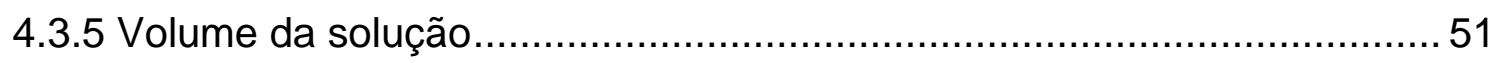

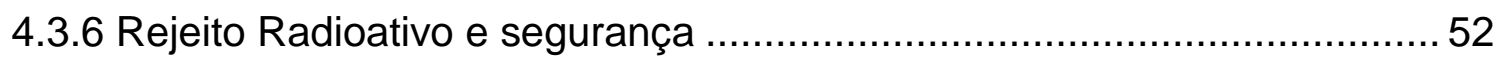

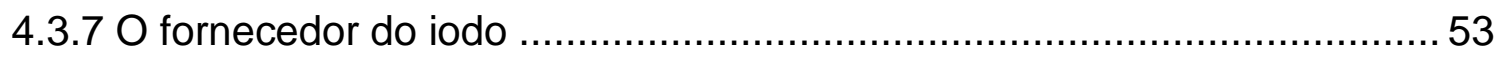

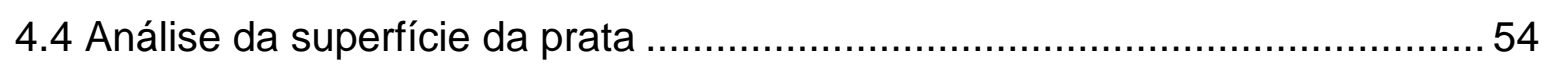

5. DISCUSSÃO

6. CONCLUSÃO

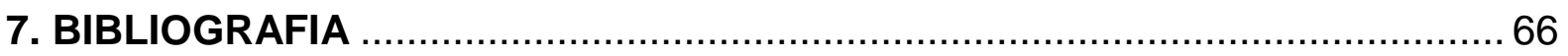




\section{INTRODUÇÃO}

\subsection{Câncer no Brasil e no mundo}

O câncer pertence a um grupo de doenças que se caracterizam pela reprodução desenfreada de células anômalas. Essas células podem se espalhar pelo corpo e resultar em morte. O câncer pode ser causado por fatores internos, como mutações genéticas hereditárias, ou por fatores externos como uso de tabaco, álcool, dieta não-saudável, entre outros. Com o avanço da tecnologia e da medicina, os diagnósticos são realizados precocemente possibilitando a descoberta da doença nos estágios iniciais. Dentre os possíveis tratamentos têm-se: cirurgia, radiação, quimioterapia, hormonioterapia, imunoterapia e terapia-alvo com agentes químicos ${ }^{[1]}$.

Os tumores malignos são responsáveis por alta taxa de óbitos em toda a população mundial. De acordo com a Sociedade Americana de Câncer uma em cada sete mortes em todo mundo é causada pelo câncer, representando mais que a AIDS, tuberculose e malária somadas. De acordo com a Agência Internacional de Pesquisa de Câncer (IARC) em 2012 constatou-se 14,1 milhões de novos casos de câncer e 8,20 milhões de mortes (cerca de 22 mil mortes por dia). Para o ano 2030, a IARC estima 21,70 milhões de novos casos, 13,20 milhões de mortes por câncer e 73 milhões de pessoas vivas com a doença. $O$ câncer de próstata é o segundo mais comum entre homens, depois do câncer de pulmão e pele, acometendo cerca de 1,10 milhões de homens no mundo e causando 307 mil mortes ${ }^{[1]}$.

No Brasil, a frequência de óbitos por câncer foi de aproximadamente 127 mil em 2013 [2]. As estimativas do Instituto Nacional do Câncer (INCA) para o ano de 2016, apontam que ocorrerão 600 mil novos casos de câncer no país. Os tipos mais incidentes (exceto o câncer de pele do tipo não melanoma), a exemplo do que ocorre no resto do mundo foram: no sexo masculino, os cânceres de próstata (cerca de 62 mil casos) e o de pulmão e os cânceres de mama e de colo do útero, no sexo feminino ${ }^{[2,3]}$. Uma das formas utilizadas para tratamento de câncer é a braquiterapia.

Embora sejam raramente discutidas, as repercussões de ordem econômica e social do câncer são grandes. As implicações para os doentes, a família e a sociedade em geral são a dor, o sofrimento, a incapacidade e a morte. Consome vasta quantidade de recursos destinados à detecção, diagnóstico e tratamento e reduzem o potencial de trabalho humano. 


\subsection{Braquiterapia e as sementes de iodo-125}

Em 1901, Pierre Curie espalhou rádio-226 impuro em seu braço por 10 horas. A pele se tornou vermelha como se fora queimada e demorou 52 dias para se reconstituir. Pierre concluiu que o material poderia ser usado para tratar lesões. Em seguida, emprestou a um médico seu amigo, Dr. Danlos, uma pequena quantidade de rádio-226, que foi usada para preparar aplicadores de superfície no tratamento de lesões de pele. Este foi o início clínico da braquiterapia ${ }^{[4]}$.

A braquiterapia é a modalidade da radioterapia em que a fonte de radiação é colocada próxima ou em contato com a região a ser tratada. A dose é liberada continuamente, durante um curto período de tempo (implantes temporários) ou durante todo o decaimento da fonte (implantes permanentes). A lesão é atingida pela maior parte da dose de radiação, atenuada sensivelmente nos tecidos sadios das vizinhanças ${ }^{[5]}$.

A braquiterapia com sementes de iodo-125 pode ser utilizada como implante permanente (próstata) ou temporário (olhos e cérebro). A fonte radioativa, em forma de semente, é constituída por:

- Um núcleo que contém o iodo-125 e um marcador radiológico, podendo ser ouro, prata, cerâmica, resina, etc;

- Uma cápsula de material biocompatível que envolve o núcleo, mais comumente de titânio ou aço inoxidável.

As sementes podem ser utilizadas para tratamento de retinoblastoma (câncer na retina ${ }^{[6]}$, gliomas (tumor no sistema nervoso central) $)^{[7]}$ e câncer na próstata ${ }^{[8]}$. No ano de 2014, cerca de 25 mil sementes de iodo-125 importadas pelo Brasil foram utilizadas para tratar câncer de próstata, 360 para retinoblasma e apenas 3 para câncer cerebral (dados na Figura 1). Existem estudos para uso dessas sementes no tratamento de câncer de mama ${ }^{[9]}$, pulmão ${ }^{[10]}$, cabeça e pescoço ${ }^{[11]}$ e no pâncreas [12]. 


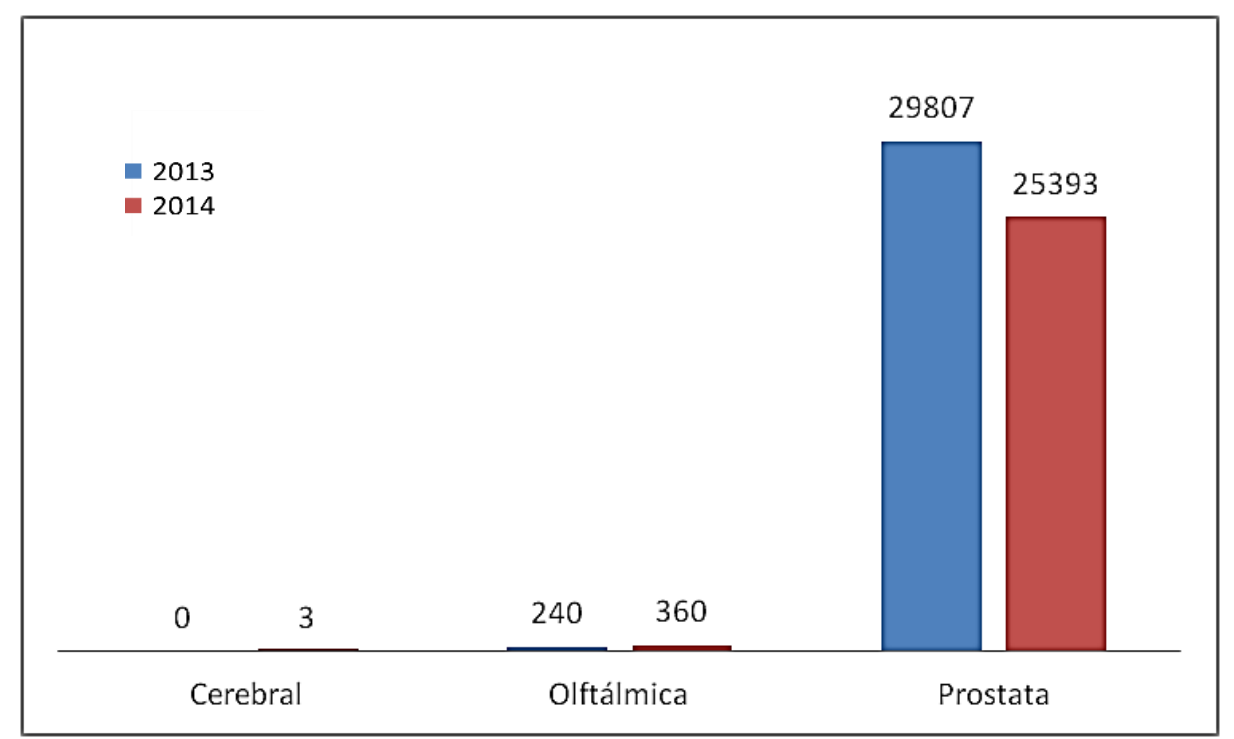

Figura 1: Gráfico com o número de sementes de iodo-125 importadas em 2013 e 2014 por tipo de tratamento (dados IPEN).

A atividade para utilização de cada semente varia para cada um dos tratamentos. Para próstata é cerca de $0,50 \mathrm{mCi}{ }^{* *}$; para cérebro pode chegar a $30 \mathrm{mCi}$ e para olho, $6 \mathrm{mCi}$. Como a maior parte das sementes de iodo-125 importadas são utilizadas para tratar câncer de próstata no Brasil, o foco desse trabalho foi para este tipo de câncer ${ }^{[8]}$. Na confecção da semente para próstata, adiciona-se durante a fase de fixação química $1 \mathrm{mCi}$ de iodo-125, já que deve-se considerar a auto absorção da atividade radioativa na prata (cerca de $20 \%$ ) e na cápsula de titânio (cerca de 14\%) ${ }^{[13]}$.

O tratamento do câncer da próstata por meio da braquiterapia tem finalidade curativa. De acordo com os resultados da literatura mundial, $95 \%$ dos pacientes tratados com essas sementes encontram-se livres da doença após 12 anos do tratamento. Além disso, como este tratamento poupa os tecidos sadios, a ocorrência de efeitos colaterais é menor em relação a outros procedimentos. Para o câncer de próstata, apenas $15 \%$ dos pacientes apresentam alteração da atividade sexual e menos de $1 \%$ apresentaram incontinência urinária. Na cirurgia estes números sobem para $45 \%$ para impotência sexual e $8 \%$ para incontinência urinária ${ }^{[8,14]}$. 
Os implantes com sementes são procedimentos de baixo impacto e não cirúrgicos. A maioria dos pacientes pode retornar à atividade normal dentro de um a três dias, com pequena ou nenhuma dor ${ }^{[8,14]}$.

\subsection{Braquiterapia de próstata}

Em 1972 o grupo de Whitmore do "Memorial Sloan-Kettering Cancer Center", nos Estados Unidos realizou estudos com as sementes de iodo-125. A equipe obteve resultados favoráveis na redução da incontinência urinária e na impotência sexual ${ }^{[4]}$. Entretanto, evidenciaram que o método não permitia uma distribuição uniforme da dose de radiação na próstata. A distribuição melhorou quando se intensificaram os estudos de dosimetria. Em 1988 um grupo formado pela Radiation Therapy Committee da American Association of Physicists in Medicine (AAPM) apresentou um documento, após revisões de diversas publicações sobre o assunto, contendo a transformação do algorítmo de cálculo de taxa de dose em grandezas físicas mensuráveis ${ }^{[4]}$.

A partir de 1983, novos avanços tecnológicos como o do ultrassom transretal e a tomografia computadorizada, impulsionaram 0 desenvolvimento da braquiterapia. Foi desenvolvido o implante permanente de sementes de iodo-125 para tratamento de câncer da próstata. O tratamento ficou mais seguro e preciso ${ }^{[4]}$.

Em 1983, o Dr. Hans Holm da Universidade de Copenhagen (Dinamarca) foi o primeiro médico no mundo a obter sucesso com um implante transperineal com sementes de iodo-125 para tratar câncer da próstata. Dr. Radge, em 1985, aplicou a técnica do Dr. Holm em Seattle (Estados Unidos) ${ }^{[4]}$.

\subsection{Grupo de braquiterapia no IPEN}

O tratamento do câncer de próstata com o implante permanente de sementes de iodo-125 cresceu expressivamente nos últimos anos. A técnica é indicada aos pacientes que apresentam o câncer no seu desenvolvimento inicial e intermediário $[4,8,15]$. Em um tratamento de câncer de próstata por braquiterapia utiliza-se cerca de 100 unidades de sementes. Elas são importadas por US\$40,00 a unidade, inviabilizando o tratamento público em larga escala [15].

Uma equipe multidisciplinar foi criada no Instituto de Pesquisas Energéticas e Nucleares - Centro de Tecnologia das Radiações (IPEN -CTR / SP) para 
desenvolver a semente de iodo-125 e implantar uma instalação para produção local. A manufatura das sementes no Brasil possibilitará baixar o custo do tratamento e viabilizá-lo para mais pacientes.

O processo de manufatura da semente é dividido em quatro partes: a primeira consiste na fase de depósito do material radioativo em um núcleo; a segunda fase é a solda da cápsula que envolve o núcleo e o marcador radiológico; a terceira parte é o controle de qualidade e a quarta a metrologia da semente (atividade). A caracterização dosimétrica também é um procedimento importante, pois garante o cálculo correto da dose no paciente.

O protótipo da nova semente em desenvolvimento no IPEN consiste em iodo-125 depositado num fio de prata (marcador radiológico) que é posicionado no interior de uma cápsula de titânio. Para a implantação da produção rotineira é necessário o desenvolvimento de metodologia para a deposição de iodo radioativo no fio de prata (núcleo da fonte). Buscou-se um método eficiente, barato e confiável. Este é o propósito deste trabalho. 


\section{OBJETIVOS}

Os objetivos deste trabalho são determinar os parâmetros necessários para implementação da fase de fixação do iodo-125 na produção rotineira de sementes utilizadas em braquiterapia. Para tal concentrou-se no estudo e desenvolvimento de um novo método de fixação do iodo-125 na superfície da prata buscando a facilidade de execução e simplicidade como características operacionais.

\section{ORIGINALIDADE DO TRABALHO}

$\mathrm{Na}$ literatura, encontram-se diversos trabalhos que discutem dosimetria da semente, aplicações das sementes de iodo-125 no tratamento de câncer, apresentação sumária de procedimentos de confecção de sementes. Também se encontram patentes que descrevem modelos de semente, sugerindo materiais para sua confecção e, em alguns casos, relatando o método de produção, porém, de maneira superficial e incompleta.

Reproduzir essas patentes não é uma opção, visto que estes processos só podem ser repetidos caso se pague os direitos envolvidos, conhecidos como royalties. O domínio tecnológico que resultará da criação de uma nova metodologia estará livre de pagamentos resultando em um produto inédito e mais barato.

Superando a questão do segredo industrial, a originalidade deste trabalho está no desenvolvimento de um novo método de preparação das fontes radioativas com a finalidade de instalação de um laboratório nacional para produção de sementes de iodo-125 utilizadas em braquiterapia. Além disso, o trabalho também apresenta e discute tópicos teóricos a partir de experiências realizadas no laboratório.

A tentativa de reproduzir métodos inédidos desenvolvidos pelo grupo de braquiterapia do IPEN ${ }^{[8,15]}$ com o iodo-131 não obtiveram resultados satisfatórios (eficiência < 20\%) comprovando a necessidade de um estudo mais específico com o iodo-125. 


\section{OBJETIVOS ESPECÍFICOS}

Objetivos específicos deste trabalham são:

- Desenvolvimento de nova metodologia para fixação do iodo-125 no núcleo de prata;

- Discusão de tópicos considerados importantes: foto-sensibilidade, comparação entre o comportamento do iodo-131 com o iodo-125, tipo do frasco utilizado na reação, influência do potencial de hidrogênio, volume da solução, o fornecedor do iodo-125 e rejeito radioativo e segurança;

- Análise da superfície da prata por MEV (Microscopia Eletrônica de Varredura) e EDX (Espectroscopia de raios X por dispersão em energia). 


\section{REVISÃO BIBLIOGRÁFICA}

\subsection{Sementes de iodo-125}

A literatura sobre as técnicas utilizadas na confecção das sementes de iodo125 é encontrada em artigos (com poucos detalhes sobre o método de fixação), na forma de patentes ou ainda em catálogos comerciais com descrições sumárias, visando à proteção do segredo industrial. No item 3.2 foram reunidas as informações disponíveis em patentes e artigos. Um resumo dos trabalhos do grupo de braquiterapia do IPEN é apresentado no item 3.4.

\subsection{Patentes e Artigos Relevantes}

As primeiras sementes de iodo- 125 foram desenvolvidas em 1965, com a patente de Lawrence, sob o título "Therapeutic metal seed containing within a radioactive isotope disposed on a carrier and method of manufacture" [16]. As dimensões e o formato da semente são descritos como as atuais (mostrados na figura 2). Como núcleo, o autor recomenda materiais plásticos como o nylon, borracha de silicone, teflon, resina de poliéster. O paládio-103, césio-131 e o iodo-125 podem ser usados como emissores de radiação. Como marcadores para exames envolvendo raios- $X$ são sugeridos o ouro e o tungstênio. $O$ aço inoxidável e o titânio são indicados como material de revestimento.

A segunda patente obtida, no ano de 1982, foi a de Kubiatowicz de título "Radioactive iodine seed" [17]. O autor sugere usar nitrato de prata ou brometo de prata para realização da troca iônica resultando em iodeto de prata $\left(\mathrm{Ag}^{125}\right)$. Recomenda diminuir a exposição à luz azul e ultravioleta, pois estas influenciam no processo. A eficiência da reação foi calculada pelo método da alíquota (ver item 4.1.5).

São descritos quatro exemplos de deposição de iodo-125 em prata para confecção da semente. No primeiro exemplo, 5 fios de prata com $70 \mathrm{~mm}$ de comprimento e 0,25 mm de diâmetro são suspensos em solução de nitrato de sódio com $1 \mathrm{~mol} / \mathrm{L}$. Também no recipiente, é posicionado um fio de platina. $O$ fio de prata é ligado no eletrodo positivo e o de platina no eletrodo negativo e uma corrente elétrica é aplicada. Este processo, conhecido como eletrodeposição, forma uma 
camada de nitrato de prata no núcleo. Eles foram cortados em pedaços de $3 \mathrm{~mm}$ de comprimento e colocados numa solução de $0,2 \mathrm{~mL}$ de iodeto de sódio ( $\left.\mathrm{Na}^{125} \mathrm{I}\right)$ e 0,01 mol/L de hidróxido de sódio. lodo não-radioativo, na forma de Nal combinado com NaOH (solução conhecida como carreadora) foram adicionados na solução e agitados por 17 horas. Os núcleos são selados com revestimento de titânio. O autor afirma uma eficiência de $97 \%$ na fixação.

No segundo exemplo, os fios de prata cortados em pedaços de $3 \mathrm{~mm}$ de comprimento e $0,5 \mathrm{~mm}$ de diâmetro são colocados em contato com solução de 1 $\mathrm{mol} / \mathrm{L}$ de nitrato de sódio. O recipiente é ligado ao eletrodo positivo e um eletrodo de contato no negativo. A corrente elétrica aplicada durante 6,5 horas. É produzida uma capa de nitrato de prata na superfície dos fios de prata. A deposição é feita do mesmo modo apresentado no primeiro exemplo.

No terceiro exemplo, os fios cortados em pedaços de $3 \mathrm{~mm}$ de comprimento e $0,5 \mathrm{~mm}$ de diâmetro são colocados em um recipiente de vidro e é adicionado $6 \mathrm{~mol} / \mathrm{L}$ de ácido clorídrico e $1 \mathrm{~mol} / \mathrm{L}$ de clorito ou hipoclorito de sódio. Após agitação de 1 hora à temperatura ambiente, uma camada de nitrato de prata é formada nos fios. Os núcleos são colocados em uma solução com iodo-125 ( $\left.\mathrm{Na}^{125} \mathrm{I}\right)$ e $10^{-4} \mathrm{~mol} / \mathrm{L}$ de hidróxido de sódio e iodo não radioativo na forma de Nal para uniformizar a distribuição do iodo (carreador). A solução é agitada por 19 horas na ausência de luz. O autor relata eficiência de fixação de $97 \%$. Os núcleos são revestidos por uma cápsula de titânio selada a plasma.

No quarto exemplo, 18 núcleos de prata de $3 \mathrm{~mm}$ de comprimento e 0,5 $\mathrm{mm}$ de diâmetro são colocados num recipiente que contém uma folha de platina, ligada no polo negativo, e um fio de platina, ligado no polo positivo. A solução de $\mathrm{Na}^{125}$ é diluída em 1,5 mL de $\mathrm{NaOH}$ com pH 10. Uma corrente de $25 \mu \mathrm{A}$ é aplicada por duas horas. O frasco deve ser constantemente agitado. A eficiência de fixação é de 97\%.

Estes modelos de semente são atualmente utilizados (Modelo 6711 da GEHealthcare) ${ }^{[18]}$.

Em 1987 foi publicada a patente "X-ray emitting interstitial implants" [19] de Russell que descreve a confecção de uma semente inerte cujo radioisótopo paládio-102 é ativado quando em contato com um fluxo de nêutrons proveniente de um reator nuclear. A semente é constituída por um invólucro de titânio, um fio de chumbo utilizado como marcador e duas esferas de 0,6 mm de diâmetro feita de pó 
de alumínio prensado com paládio-102 (74\% de pureza). O paládio-102 pode ser ativado em paládio-103 antes ou depois da montagem.

A patente "Process for depositing I-125 onto a substrate used to manufacture I-125 sources" [20] publicada por McGovern et al em 1988, utiliza fita de grafite, fita de grafite impregnada com carvão, fita de grafite impregnada com prata, fio de platina ou fio de cobre. Estes materiais são posicionados no interior de um vaso de pressão em que é bombeado o gás xenônio-125 que decai para iodo-125, depositando na superfície do núcleo.

Suthanthiran descreve na patente "Device and method for encapsulanting radioactive materials" de 1990 [21], uma cápsula de aço inoxidável ou titânio composta de duas partes com uma extremidade fechada. Uma das partes é colocada no interior da outra com interferência mecânica provendo uma selagem sem necessidade de soldagem. Em outra patente do mesmo autor (em co-autoria com Lakshman) "Pellet for a radioactive seed" [22] de 1992, são descritos três exemplos de sementes. No primeiro exemplo, é usado um núcleo de tungstênio, que também funciona como marcador em exames de imagem, de $4 \mathrm{~mm}$ de comprimento e 0,25 $\mathrm{mm}$ de diâmetro. O fio foi revestido com $25 \%$ de politirosina e $75 \%$ de acetato de celulose. O fio revestido é imerso em $1 \mathrm{~mL}$ de iodo-125 em solução de $\mathrm{Na}^{125}$ I de $1000 \mathrm{mCi} / \mathrm{mL}$. Após a secagem, o fio reage com $1 \mathrm{~mL}$ de cloramina- $\mathrm{T}(75 \mathrm{mg} / \mathrm{mL}$ ) na temperatura ambiente. Bissulfito de sódio ( $1 \mu \mathrm{L}-50 \mathrm{mg} / \mathrm{mL})$ é adicionado na solução. Depois o fio é secado, cortado e revestido por cápsula de titânio.

No segundo exemplo, o fio de tungstênio já revestido é colocado em solução de $\mathrm{Na}^{125}$ de $500 \mathrm{mCi} / \mathrm{mL}$. O iodeto de sódio radioativo é adicionado de 0,5 em $0,5 \mathrm{mCi}$ com intervalos de 30 minutos.

No terceiro exemplo, são misturados $50 \mathrm{~mL}$ de poli-D-tirosina e $2 \mathrm{mg} / \mathrm{mL}$ em $0,1 \mathrm{~mol} / \mathrm{L} \mathrm{NaOH}$. São adicionados na solução $50 \mu \mathrm{L}$ a $1 \mathrm{~mol} / \mathrm{L}$ de ácido clorídrico e $50 \mu \mathrm{L}$ a 0,2 mol/L de borato resultando num $\mathrm{pH}$ final de 7,9. São acrescentados $2 \mu \mathrm{L}$ de $\mathrm{Na}^{125}$ ativado com $500 \mathrm{mCi} / \mathrm{mL}$ e $50 \mathrm{~mL}$ de cloramina-T (30 mg/mL $\mathrm{H}_{2} \mathrm{O}$ ). A mistura reage por 30 segundos e metabissulfeto de sódio $\left(10 \mathrm{mg} / \mathrm{mL} \mathrm{H}_{2} \mathrm{O}\right.$ ) é usado para parar a reação. A mistura é filtrada a baixa pressão. Forma-se um filme nos tubos do filtro que é secado e aderido a uma vareta de tungstênio. Os modelos são utilizados pela Best Industries.

Cutrer publicou duas patentes, "Laser welded brachytherapy source and method of making the same" [23] em 1999 e "Radioactive seed with multiple markers 
and method for using the same" [24] em 2003. Ambas apresentam uma semente que utiliza um núcleo composto de quatro esferas de resina em que o material radioativo, iodo-125 ou paládio-103, é incorporado. Esferas de prata ou ouro são utilizadas como marcador para localização da fonte. A posição das esferas depende da atividade final desejada. Poucos detalhes da reação de fixação são apresentados. O modelo é utilizado pela Mentor Corp.

Na patente, "Encapsuled low-energy brachytherapy sources" [25] publicada em 2000, Robertson apresentou um modelo para fontes de baixa taxa de dose contendo quatro esferas (diâmetro de 0,65 mm) de zeolita como iodo-125 ou paládio-103, separadas, duas a duas, por um "plug" anelar de titânio com um núcleo concêntrico de uma liga de platina e irídio (marcador). As esferas são imersas na solução radioativa de $2 \mathrm{mCi}$ com hidróxido de amônia de $\mathrm{pH}$ 10,5. Depois são secas em um forno a $100^{\circ} \mathrm{C}$ por uma hora e por mais uma hora a $350^{\circ} \mathrm{C}$. O autor afirma que a invenção considerou diversos problemas de anisotropia associadas à atenuação da radiação pelo encapsulamento.

Também em 2000, Slater et al publicaram a patente "Radioactive therapeutic seed having selective marker configuration" [26], em que descrevem uma semente com quatro esferas de titânio, alumínio ou vidro em que o material radioativo está depositado. As esferas são separadas, duas a duas, por um marcador de gadolínio (também visível em ressonância magnética) com uma cavidade no seu interior que permite a colocação de um segundo marcador. A cápsula de titânio é dividida em duas metades. Um "plug" anular de titânio é colocado na parte central para soldagem da semente.

Na patente "Process for preparing iodine-125 seeds source carrier bar" [27] publicada em 2000, os autores utilizam peróxido de hidrogênio e ácido clorídrico como oxidante e formador de $\mathrm{AgCl}$, respectivamente. Os autores afirmam que, apesar da maioria das reações com iodo ser realizada em $\mathrm{pH}$ básico, o pH ácido favorece a formação de $\mathrm{Ag}^{125}$ aumentando a eficiência. No primeiro exemplo, uma solução de $30 \% \mathrm{H}_{2} \mathrm{O}_{2}(2 \mathrm{~mL})$ foi adicionada a $2,5 \mathrm{~mL}$ de $\mathrm{HCl}(6 \mathrm{~mol} / \mathrm{L})$ contendo 20 núcleos de prata de $3 \mathrm{~mm}$. A reação foi agitada por 5 horas. Os núcleos foram lavados com acetona e colocados em solução de $\mathrm{Na}^{125} \mathrm{com} 100 \mu \mathrm{g} / \mathrm{mL}$ (10 mL- $50 \mathrm{mCi})$ por 18 horas. Os autores afirmam 99\% de eficiência. O segundo exemplo segue a mesma metodologia mudando as quantidades: 7:12 como proporção de $\mathrm{H}_{2} \mathrm{O}_{2}$ e $\mathrm{HCl}, \mathrm{Na}^{125}$ I com $15 \mu \mathrm{g} / \mathrm{mL}$ e $\mathrm{pH}$ controlado com ácido acético 
para 7 resultando em $96,2 \%$ de eficiência. No terceiro exemplo foi utilizado 7:9 de $\mathrm{H}_{2} \mathrm{O}_{2}$ e $\mathrm{HCl}, 150 \mu \mathrm{g} / \mathrm{mL}$ e $\mathrm{pH}$ controlado com ácido acético para 6 resultando em $99,1 \%$ de eficiência. A eficiência da reação foi calculada pelo método da alíquota (ver item 4.1.5).

Os autores da patente "lodine-125 seed medicine for intervention treatment and its preparation" [13] apresentaram, em 2001, 3 exemplos de semente de iodo-125. No primeiro exemplo, os fios de prata foram esmerilhados até atingirem 0,3mm de diâmetro. Em um frasco âmbar, os fios foram submersos em $30 \mathrm{~mL}$ solução com $1 \mathrm{~mol} / \mathrm{L}$ de clorato de sódio e $1 \mathrm{~mol} / \mathrm{L}$ de ácido clorídrico e agitados por 75 minutos. Os núcleos foram então lavados três vezes com água deionizada e etanol. 20 núcleos foram colocados em solução de $200 \mu \mathrm{L}$ com $200 \mathrm{mCi}$ de iodo-125 de pH 12 e $50 \mu \mathrm{g}$ de iodeto de potássio (carreador- iodeto não radioativo) por 22 horas. Os núcleos foram então lavados com água e etanol.

No segundo exemplo, um fio de $30 \mathrm{~cm}$ de comprimento e $0,3 \mathrm{~mm}$ de diâmetro foi posicionado em uma cuba eletrolítica contendo $1 \mathrm{~mol} / \mathrm{L}$ de nitrato de sódio. $\mathrm{O}$ fio de prata foi conectado no polo positivo e um fio de platina foi conectado no polo negativo. A corrente elétrica foi ligada por 90 minutos (eletrodos com $6 \mathrm{~V}$ e corrente 0,5 A). O fio de prata, agora com uma camada superficial homogênea de $\mathrm{AgCl}$, foi cortado em pequenos núcleos de $3 \mathrm{~mm}$ e lavados três vezes com água deionizada e etanol. A fixação foi realizada da mesma maneira que no exemplo 1.

No terceiro exemplo, 20 fios de prata já cortados e lavados foram colocados em solução de iodeto de potássio $(0,385 \mathrm{~g} / \mathrm{L}$, pH 13,5) e com $200 \mathrm{mCi}$ de iodo-125. A reação foi realizada sob atmosfera de oxigênio (1atm) por 24 horas. A eficiência da reação foi calculada pelo método da alíquota (ver item 4.1.5), mas o valor não foi relatado.

Na patente de 2001 "Preparation process of source core of iodine-125 granule sealed seed source" [28] o autor apresenta uma fonte com um núcleo de prata de $3 \mathrm{~mm}$. A reação mistura somente um núcleo com uma solução de $225 \mathrm{mCi}$ de $\mathrm{Na}^{125}$ com $\mathrm{pH} 8$ e temperatura $31^{\circ} \mathrm{C}$. A eficiência da reação foi calculada pelo método da alíquota (ver item 4.1.5) em 92,2\%. Os núcleos são então colocados em um equipamento selado com difusão de ar por 36 horas. $O$ autor afirma que este passo é fundamental, uma vez que se o núcleo de prata for colocado num frasco de vidro, $30 \%$ do iodo-125 ficaria aderido. Quando este método é realizado, a perda cai para 
1\%. O autor afirma que o método rende $30 \%$ de fixação. A eficiência da reação foi calculada pelo método da comparação (ver item 4.1.5).

Em 2002, Singh et al publicaram a patente "Radioactive seeds for brachytherapy and a process for making the same" [29] que apresenta uma semente composta por dois cilindros de resina contendo iodo-125 ou paládio-103. Uma mistura de resina com os radionuclídeos é preparada e, em seguida, curada. Entre os cilindros de resina é colocado um marcador que pode ser de prata, ouro, tungstênio ou chumbo.

Ziegler et al apresentaram, na sua patente "Medical radioactive iodine-125 miniature radiation source and methods of producing the same" [30] publicada em 2002, uma semente composta por uma matriz de material inorgânico poroso combinada com cátions, tal como óxido de alumínio misturado com vidro. Os poros contêm o iodo-125 insolúvel, na forma de iodeto de prata, iodeto de chumbo, iodeto de bismuto, iodeto de tálio ou iodeto de cobre. Esta matriz é de formato cilíndrico com um núcleo concêntrico de ouro (marcador) de diâmetro 0,1 a 0,7 mm. Como exemplo, $110 \mathrm{mg}$ de óxido de alumínio (diâmetro do grão 1-5 $\mu \mathrm{m}$ ) são colocados e um vaso (capilar) que é aquecido a $70^{\circ} \mathrm{C}$ e misturado com $60 \mathrm{mg}$ de celulose em pó e $30 \mathrm{mg}$ de fécula ou goma. São acrescentados mais $100 \mathrm{mg}$ de parafina e água até se formar uma massa consistente para ser colocada na máquina de moldar.

Manolkar et al no artigo "Comparison of methods for preparation of $\mathrm{I}^{125}$ brachytherapy source cores for the treatment of eye cancer" ${ }^{[31]}$ descreve dois modelos de semente. No primeiro método, um fio de prata posicionado em um recipiente com $30 \mu \mathrm{L}$ de uma solução de iodeto de sódio com $3,5 \mathrm{mCi}$ de atividade e $650 \mu \mathrm{L}$ de sulfito de sódio a $0,001 \mathrm{~mol} / \mathrm{L}$. Na solução, foi colocado um agitador magnético. Um fio de platina foi ligado no eletrodo negativo e o fio de prata num positivo e uma corrente atravessa o sistema fazendo com que o iodo-125 se deposite na prata. No segundo modelo, microesferas de alumina foram tratadas com $10^{-3} \mathrm{~mol} / \mathrm{L}$ de nitrato de sódio. Depois elas foram imersas em $30 \mu \mathrm{L}$ de solução de iodo-125 e 0,1 mL de uma mistura de chloramina-T dissolvida em $10^{-3} \mathrm{~mol} / \mathrm{L}$ de nitrato de sódio. Uma solução radioativa contendo iodo-125 foi adicionada e agitada por 4 horas a temperatura ambiente. As esferas foram lavadas em solução de nitrato de sódio e secas à temperatura ambiente.

Mathew et al publicaram em 2002 o artigo "A novel approach for the adsorption of iodine-125 on silver wire as matrix for brachytherapy source for the treatment of 
eye and prostate cancer" [32]. Eles descrevem um processo de deposição de iodo-125 em fios de prata envolvidos com paládio. Os fios, depois de prontos e cortados, são tratados com $100 \mathrm{~mL}$ de $\mathrm{HCl}$ a $3 \mathrm{~mol} / \mathrm{L}$ e posteriormente lavados com água. Os fios são secados com uma lâmpada de infravermelho. Os núcleos tratados são colocados em uma solução de $40 \mu \mathrm{L}$ de iodeto de potássio $(\mathrm{KI})$ ativado, $\mathrm{K}^{125}$, com $4 \mathrm{mCi}$ e $5 \mu \mathrm{g}$ em $10 \mu \mathrm{l}$ de $\mathrm{KI}$ não radioativo (carreador). O volume de reação para imersão dos fios foi aumentado de $50 \mathrm{~mL}$ para $500 \mathrm{~mL}$ pela adição de água destilada duas vezes. Aplicou-se $60^{\circ} \mathrm{C}$ por cerca de $6 \mathrm{~h}$. O processo teve $100 \%$ de eficiência ${ }^{[32]}$. A eficiência da reação foi calculada pelo método da alíquota (ver item 4.1.5).

Em diversas publicações ${ }^{[33-35]}$ o grupo chefiado por Cieszykowska apresentou dois novos métodos de preparação de sementes de iodo-125. O primeiro é um aplicador oftálmico com iodo-125 fixado por eletrólise interna numa concha de prata. A fonte é hermeticamente fechada dentro de uma cápsula de acrílico também em forma esférica. As medições de taxa de dose indicam que a atividade total foi incorporada. No segundo método, os autores utilizam a eletrólise interna aplicada nos núcleos de prata com as dimensões de $3 \mathrm{~mm}$ de comprimento e 0,5 mm de diâmetro e para fios inteiros de $30 \mathrm{~mm}$ de comprimento. A célula usada para fixação consiste de um ânodo de prata inserido em um cadinho de platina (cátodo). A solução de $20 \mathrm{~mL}$ de iodeto de sódio ativado foi formulada a partir de hidróxido de sódio com $0,01 \mathrm{~mol} / \mathrm{L}$. Os resultados obtidos indicam que o fio de prata deve ser primeiro revestido com iodo-125 (99\% de eficiência) e depois cortado em pedaços $3 \mathrm{~mm}$ de comprimento (54\% de eficiência). A eficiência da reação foi calculada pelo método da alíquota (ver item 4.1.5).

O documento "TECDOC-1512: Production Techniques and Quality Control of Sealed Radioactive Sources of Palladium-103, Iodine-125, Iridium-192 and Ytterbium-169" [35] publicado pela Agência Internacional de Energia Atômica (IAEA) trouxe diversos trabalhos de desenvolvimento de novas fontes. Além do trabalho chefiado por Cieszykowska (Polônia), encontram-se:

- "Development of I ${ }^{125}$ Seed Source for Treatment of Eye and Prostate Cancer" Z.M. MEHDIKHANI, S. SHEIBANI (Irã): A fixação do iodo radioativo está sendo estudada em fios de prata envolvidos por titânio. Estas experiências 
demonstraram a fixação consistente de iodo-125 (83\%). O método está em processo de otimização. A eficiência da reação foi calculada pelo método da alíquota (ver item 4.1.5);

- "I25 Sublimation/Chemosorption Technique for Miniature Source Core Production" P.V. CHAKROV, V.S. ZHDANOV (Cazaquiatão): A principal característica do estudo realizado foi a aplicação do processo de vácuo, que inclui a sublimação térmica de iodo livre resultando em sua deposição química no núcleo de prata. Os estudos continuam;

- "Development of Miniature Radiation Sources for Medical and Non-Destructive Testing Applications" K.J. SON, J.S. LEE, U.J. PARK, S.B. HONG, K.S. SEO, H.S. HAN (Coréia do Sul): Um meio carreador de $\mathrm{Al}_{2} \mathrm{O}_{3}$ (óxido de alumínio) com prata (15\% do peso) em pó foi desenvolvido. A porosidade do material é de aproximadamente $10 \%$. Após serem montadas pequenas hastes, o material entra em contato com uma solução radioativa com $5 \mathrm{mCi} / 5 \mu \mathrm{L}$ por 4 horas resultando em fixação de $95 \%$. A eficiência da reação foi calculada pelo método da alíquota (ver item 4.1.5);

- "Production of $\mathrm{I}^{125}$ Seed Sources For Brachytherapy Uses" M. BENITES, J. MIRANDA, R. CONDOR, L. CAVERO, R. MARTÍNEZ (Perú): Desenvolveram um processo baseado no do Irã, Mathew et al [32] e Saxena et al ${ }^{[36]}$. As condições ideais para o revestimento dos fios de prata com paládio foram obtidas, sendo estas as seguintes: núcleo de prata é revestido com $\mathrm{PdCl}_{2}$ 0,1 mol/L, pH de 5,5 a 6,5 a uma temperatura de $100^{\circ} \mathrm{C}$. A concentração da solução carredora de $\mathrm{KI}$ foi de $0,03 \mathrm{~mol} / \mathrm{L}$. O tempo de reação foi de 6 horas em temperatura de $70^{\circ} \mathrm{C}$. A eficiência foi de $98,24 \%$. A eficiência da reação foi calculada pelo método da alíquota (ver item 4.1.5). 
Wang relatou na patente de 2007 "Technique for preparing coating of iodine125 sealed seed source silver carrier rod" [37] uma nova metodologia que utiliza uma solução $\mathrm{NaCl} / \mathrm{NaBr}$ na proporção 1,2/3,5 para 1, respectivamente. À essa solução, foi acrescentado $\mathrm{ICl}_{2}{ }^{-}$na concentração de $0.005-0,03 \mathrm{~mol} / \mathrm{L}$ e iodo radioativo com atividade $60-80 \%$ maior que o esperado (100\% representa $1 \mathrm{mCi} /$ núcleo). A reação foi agitada em um rolador especial em que a rotação e o ângulo puderam ser variados. O autor utilizou de 20-60 rev/min 20-40 durante 15-30 minutos. Segundo o autor, os núcleos devem ser selados em cápsula de titânio em, no máximo, 15-30 minutos. A eficiência da reação foi calculada pelo método da alíquota (ver item 4.1.5).

Xiaolong et. al. relatam na patente de 2008, "Method of preparing iodine-125 sealing seed source core" [38], uma nova metodologia em que 120 núcleos de prata foram colocados em um frasco de vidro com $2 \mathrm{~mL}$ de hipoclorito de sódio $(60 \%)$ por 1 hora. Os fios, contendo uma camada de $\mathrm{AgCl}$, foram lavados com água deionizada pesada e secados com a utilização de um soprador. Em outro frasco de vidro, os 120 fios em solução de $1 \mathrm{~g} / \mathrm{L}$ de iodeto de sódio $(240 \mu \mathrm{L})$ com $750 \mu \mathrm{L}$ de tampão acetato ( $\mathrm{pH}$ 2-5) e $100 \mathrm{mCi}$ de $\mathrm{Na}^{125}$ r reagiram por 1 hora. A eficiência da reação foi calculada pelo método da comparação (ver item 4.1.5), mas o valor não foi relatado.

A patente de 2004 publicada por Yan Kun Seoul com o título "Preparation method of therapy used iodine-125 sealed seed source core" [39] apresenta nove variações na mesma metodologia. 100 núcleos de prata de $3 \mathrm{~mm}$ de comprimento e $0.5 \mathrm{~mm}$ de diâmetro lavados com acetona reagem com a solução $\mathbf{A}$ e $\mathbf{B}$ por $\mathbf{C}$ horas. Os fios revestidos por uma camada de nitrato de prata foram lavados com água deionizada 3 vezes. Os 100 núcleos foram transferidos para outro frasco com a solução $\mathbf{D}, \mathbf{E}$ e solução radioativa com $\mathbf{F}$ de atividade. $\mathrm{O}$ pH foi corrigido para $\mathbf{G}$ com uma solução de $\mathrm{NaOH}$ de $0,01 \mathrm{~mol} / \mathrm{L}$. A reação reagiu sob agitação por $\mathbf{H}$ horas. $\mathrm{O}$ autor afirma mais de $98 \%$ de fixação em todas as variações. A eficiência da reação foi calculada pelo método da alíquota (ver item 4.1.5). Os dados A-H encontram-se na tabela 1. 
Tabela 1: Dados dos itens A-H da patente "Preparation method of therapy used iodine- 125 sealed seed source core".

\begin{tabular}{|c|c|c|c|c|c|c|c|c|}
\hline & A & B & C & D & $E$ & $F$ & $\mathbf{G}$ & H \\
\hline $\begin{array}{c}\text { Exemplo } \\
1\end{array}$ & $\begin{array}{c}1 \mathrm{~mL} \text { de } \\
\text { ferricianeto } \\
\text { de potássio } \\
\text { com } 10 \mathrm{~g} / \mathrm{L}\end{array}$ & $\begin{array}{c}4 \mathrm{~mL} \text { de } \\
\text { nitrato de } \\
\text { sódio com } \\
2 \mathrm{~mol} / \mathrm{L}\end{array}$ & $5 \mathrm{~h}$ & $\begin{array}{c}0,2 \mathrm{~mL} \text { de } \\
\text { iodeto de } \\
\text { sódio com } \\
10 \mathrm{~mol} / \mathrm{L}\end{array}$ & $\begin{array}{c}0,2 \mathrm{~mL} \text { de } \\
\text { brometo de } \\
\text { sódio com } \\
20 \mathrm{~g} / \mathrm{L}\end{array}$ & $\begin{array}{l}100 \\
\mathrm{mCi}\end{array}$ & 10 & $9 \mathrm{~h}$ \\
\hline $\begin{array}{c}\text { Exemplo } \\
2\end{array}$ & $\begin{array}{c}12 \mathrm{~mL} \text { de } \\
\text { ferricianeto } \\
\text { de potássio } \\
\text { com } 1 \mathrm{~g} / \mathrm{L}\end{array}$ & $\begin{array}{c}1 \mathrm{~mL} \text { de } \\
\text { nitrato de } \\
\text { sódio com } \\
6 \mathrm{~mol} / \mathrm{L}\end{array}$ & $8 \mathrm{~h}$ & $\begin{array}{l}0,05 \mathrm{~mL} \text { de } \\
\text { iodeto de } \\
\text { sódio com } \\
100 \mathrm{~g} / \mathrm{L}\end{array}$ & $\begin{array}{c}0,05 \mathrm{~mL} \text { de } \\
\text { brometo de } \\
\text { sódio com } \\
150 \mathrm{~g} / \mathrm{L}\end{array}$ & $\begin{array}{l}200 \\
\mathrm{mCi}\end{array}$ & 8 & $10 \mathrm{~h}$ \\
\hline $\begin{array}{c}\text { Exemplo } \\
3\end{array}$ & $\begin{array}{l}0,01 \mathrm{~mL} \text { de } \\
\text { ferricianeto } \\
\text { de potássio } \\
\text { com } 100 \mathrm{~g} / \mathrm{L}\end{array}$ & $\begin{array}{c}10 \mathrm{~mL} \text { de } \\
\text { nitrato de } \\
\text { potássio } \\
\text { com } 0,1 \\
\mathrm{~mol} / \mathrm{L}\end{array}$ & $3 \mathrm{~h}$ & $\begin{array}{c}17 \mathrm{~mL} \text { de } \\
\text { iodeto de } \\
\text { potássio } \\
\text { com } 1 \mathrm{~g} / \mathrm{L}\end{array}$ & $\begin{array}{c}17 \mathrm{~mL} \text { de } \\
\text { brometo de } \\
\text { potássio } \\
\text { com } 1 \mathrm{~g} / \mathrm{L}\end{array}$ & $\begin{array}{c}10 \\
\mathrm{mCi}\end{array}$ & 9 & $8 \mathrm{~h}$ \\
\hline $\begin{array}{c}\text { Exemplo } \\
4\end{array}$ & $\begin{array}{c}1 \mathrm{~mL} \text { de } \\
\text { ferricianeto } \\
\text { de potássio } \\
\text { com } 30 \mathrm{~g} / \mathrm{L}\end{array}$ & $\begin{array}{c}4 \mathrm{~mL} \text { de } \\
\text { nitrato de } \\
\text { césio com } \\
2 \mathrm{~mol} / \mathrm{L}\end{array}$ & $5 \mathrm{~h}$ & $\begin{array}{c}15 \mathrm{~mL} \text { de } \\
\text { iodeto de } \\
\text { sódio com } \\
1 \mathrm{~g} / \mathrm{L}\end{array}$ & $\begin{array}{c}1 \mathrm{~mL} \text { de } \\
\text { brometo de } \\
\text { sódio com } \\
30 \mathrm{~g} / \mathrm{L}\end{array}$ & $\begin{array}{l}400 \\
\mathrm{mCi}\end{array}$ & 9 & $9 \mathrm{~h}$ \\
\hline $\begin{array}{c}\text { Exemplo } \\
5\end{array}$ & $\begin{array}{l}2 \mathrm{~mL} \text { de } \\
\text { ferricianeto } \\
\text { de potássio } \\
\text { com } 10 \mathrm{~g} / \mathrm{L}\end{array}$ & $\begin{array}{c}4 \mathrm{~mL} \text { de } \\
\text { nitrato de } \\
\text { sódio com } \\
2 \mathrm{~mol} / \mathrm{L}\end{array}$ & $5 \mathrm{~h}$ & $\begin{array}{c}15 \mathrm{~mL} \text { de } \\
\text { iodeto de } \\
\text { sódio com } \\
1 \mathrm{~g} / \mathrm{L}\end{array}$ & $\begin{array}{c}10,3 \mathrm{~mL} \text { de } \\
\text { brometo de } \\
\text { sódio com } \\
2 \mathrm{~g} / \mathrm{L}\end{array}$ & $\begin{array}{l}200 \\
\mathrm{mCi}\end{array}$ & 9 & $9 \mathrm{~h}$ \\
\hline $\begin{array}{c}\text { Exemplo } \\
6\end{array}$ & $\begin{array}{c}2 \mathrm{~mL} \text { de } \\
\text { ferricianeto } \\
\text { de potássio } \\
\text { com } 10 \mathrm{~g} / \mathrm{L}\end{array}$ & $\begin{array}{c}4 \mathrm{~mL} \text { de } \\
\text { nitrato de } \\
\text { sódio com } \\
2 \mathrm{~mol} / \mathrm{L}\end{array}$ & $6 \mathrm{~h}$ & $\begin{array}{c}15 \mathrm{~mL} \text { de } \\
\text { iodeto de } \\
\text { sódio com } \\
1 \mathrm{~g} / \mathrm{L}\end{array}$ & $\begin{array}{c}10,3 \mathrm{~mL} \text { de } \\
\text { brometo de } \\
\text { sódio com } \\
2 \mathrm{~g} / \mathrm{L}\end{array}$ & $\begin{array}{l}200 \\
\mathrm{mCi}\end{array}$ & 9 & $9 \mathrm{~h}$ \\
\hline $\begin{array}{c}\text { Exemplo } \\
7\end{array}$ & $\begin{array}{l}2 \mathrm{~mL} \text { de } \\
\text { ferricianeto } \\
\text { de potássio } \\
\text { com } 10 \mathrm{~g} / \mathrm{L}\end{array}$ & $\begin{array}{c}4 \mathrm{~mL} \text { de } \\
\text { nitrato de } \\
\text { sódio com } \\
2 \mathrm{~mol} / \mathrm{L}\end{array}$ & $6 \mathrm{~h}$ & $\begin{array}{c}15 \mathrm{~mL} \text { de } \\
\text { iodeto de } \\
\text { sódio com } \\
1 \mathrm{~g} / \mathrm{L}\end{array}$ & $\begin{array}{l}12,87 \mathrm{~mL} \text { de } \\
\text { brometo de } \\
\text { sódio com } \\
2 \mathrm{~g} / \mathrm{L}\end{array}$ & $\begin{array}{l}200 \\
\mathrm{mCi}\end{array}$ & 9 & $9 \mathrm{~h}$ \\
\hline $\begin{array}{c}\text { Exemplo } \\
8\end{array}$ & $\begin{array}{l}2 \mathrm{~mL} \text { de } \\
\text { ferricianeto } \\
\text { de potássio } \\
\text { com } 10 \mathrm{~g} / \mathrm{L}\end{array}$ & $\begin{array}{c}4 \mathrm{~mL} \text { de } \\
\text { nitrato de } \\
\text { sódio com } \\
2 \mathrm{~mol} / \mathrm{L}\end{array}$ & $6 \mathrm{~h}$ & $\begin{array}{c}15 \mathrm{~mL} \text { de } \\
\text { iodeto de } \\
\text { sódio com } \\
1 \mathrm{~g} / \mathrm{L}\end{array}$ & $\begin{array}{c}15,45 \mathrm{~mL} \text { de } \\
\text { brometo de } \\
\text { sódio com } 2 \\
\mathrm{~g} / \mathrm{L}\end{array}$ & $\begin{array}{l}200 \\
\mathrm{mCi}\end{array}$ & 9 & $9 \mathrm{~h}$ \\
\hline $\begin{array}{c}\text { Exemplo } \\
9\end{array}$ & $\begin{array}{l}2 \mathrm{~mL} \text { de } \\
\text { ferricianeto } \\
\text { de potássio } \\
\text { com } 10 \mathrm{~g} / \mathrm{L}\end{array}$ & $\begin{array}{c}4 \mathrm{~mL} \text { de } \\
\text { nitrato de } \\
\text { sódio com } \\
2 \mathrm{~mol} / \mathrm{L}\end{array}$ & $6 \mathrm{~h}$ & $\begin{array}{c}15 \mathrm{~mL} \text { de } \\
\text { iodeto de } \\
\text { sódio com } \\
1 \mathrm{~g} / \mathrm{L}\end{array}$ & $\begin{array}{c}25,75 \mathrm{~mL} \text { de } \\
\text { brometo de } \\
\text { sódio com } \\
2 \mathrm{~g} / \mathrm{L}\end{array}$ & $\begin{array}{l}200 \\
\mathrm{mCi}\end{array}$ & 9 & $9 \mathrm{~h}$ \\
\hline
\end{tabular}

O mesmo autor publicou em 2015 a patente "Method for preparing iodine-125 sealed seed source core" ${ }^{[40]}$ em que apresenta um núcleo de prata de 2-3,5 mm de comprimento com o iodo-125 fixado. A reação consiste em acrescentar 0,15 a 1,5 mL com 0,01 a 3 mol por núcleo de solução de citrato de sódio ou potássio 
com 0,005 a $1 \mathrm{~mol} / \mathrm{L}$ de persulfato de oxigênio. A reação foi agitada por 2-5 minutos e brometo de sódio ou potássio é adicionado em concentração de 0,001 a $4 \mathrm{~mol} / \mathrm{L}$ (0.02-0.5 mL). Também é adicionado iodeto de sódio ou potássio com volume de 0,04-1,5 mL e atividade de 100-1000 mCi/mL. O pH foi ajustado de 8 a 12 e a reação foi agitada de 3-20 min. Os núcleos foram então lavados com acetona, água ou álcool de 2 a 4 vezes. Todos os frascos utilizados são de quartzo. A eficiência da reação foi calculada pelo método da comparação (ver item 4.1.5), mas o valor não foi relatado.

Em 2009, Saxena et al publicaram o artigo "Development of a new design I ${ }^{125}$ brachytherapy seed for its application in the treatment of eye and prostate cancer" [36] que descreve uma semente feita com esferas de prata (diâmetro de 0,5 mm) revestidas com paládio. Uma solução de iodeto de sódio radioativa dissolvida em hidróxido de sódio fica em contato durante um tempo e temperatura não estipulado pelo autor. Depois as esferas são lavadas com água destilada a $50^{\circ} \mathrm{C}$ e revestidas com poliestireno. O autor afirma $85 \%$ de eficiência. Saxena também publicou em 2012 o artigo "Development of a 125I source for its application in bone densitometry" [41] que descreve uma fonte com núcleo de prata revestido com paládio. Poucas informações sobre o processo são dadas. A solução de iodo contém $250 \mu \mathrm{L}$ com atividades mantidas entre $100-200 \mathrm{mCi}$ por $\mathrm{mL}$ de solução. A reação foi feita sob temperatura de $65^{\circ} \mathrm{C}$ durante 6 horas. $35 \mu \mathrm{g}$ de carreador foi acrescentado resultando em $76 \%$ de eficiência ${ }^{[41]}$. A eficiência da reação foi calculada pelo método da comparação (ver item 4.1.5).

Com a publicação "New material for low-dose brachytherapy seeds: Xe-doped amorphous carbon films with post-growth neutron activaded ${ }^{125}{ }^{\text {" }}{ }^{[42]}$ os autores apresentam um novo material a ser utilizado como núcleo. O uso de matrizes poliméricas se apresenta como uma tendência, visto que o iodo se prende com mais facilidade. Porém os autores não utilizaram um marcador radiológico, o que torna o formato impossível de ser utilizado para localização nos implantes de próstata. $O$ material composto de filme de carbono impregnado com xenônio passa por ativação em um reator nuclear resultando em iodo-125.

O grupo sul-coreano, Choi et. al. ${ }^{43]}$, publicou em 2012 a patente entitulada "Method of preparing iodine seed for treating eye disease or cancer, and iodine seed prepared thereby". A metodologia foi dividida em três partes. A parte 1 consiste na preparação da solução de iodo-125: a solução de $\mathrm{Na}^{125}$ com $50 \mathrm{mCi}$ por $0,5 \mathrm{~mL}$ foi diluída em uma solução carreadora de Nal correspondente a quantidade de iodeto 
presente em 2000 mCi. O sal de iodeto de sódio foi dissolvido em solução de $\mathrm{NaOH}$ com $0,01 \mathrm{~mol} / \mathrm{L}$. Na parte 2, os autores citam 3 exemplos da preparação utilizada nos núcleos de prata:

- Exemplo 1: Núcleos de prata (99\% prata) com 3mm de comprimento foram lavados duas vezes com água destilada em temperatura ambiente por 3 minutos num banho ultrassônico. A água é então drenada e etanol foi adicionado para facilitar a secagem. Uma solução de fosfato de sódio $(0,68 \mathrm{~g} / 10 \mathrm{~mL})$, oxalato de sódio $(0,56 \mathrm{~g} / 10 \mathrm{~mL})$, carbonato de sódio $(0,44 \mathrm{~g} / 10 \mathrm{~mL})$, azida de sódio $\left(\mathrm{NaN}_{3}-0,27 \mathrm{~g} / 10 \mathrm{~mL}\right)$ ou arsenato de sódio $(1,30 \mathrm{~g} / \mathrm{mL})$ foi adicionada em um frasco com 10 núcleos de prata e agitadas com 200 rpm por 62 horas. Os autores também relatam que pode se adicionar $50 \mu \mathrm{L}$ de solução de $30 \%$ de peróxido de hidrogênio para facilitar a oxidação. Os núcleos foram lavados com água e acetona;

- Exemplo 2: Núcleos de prata (99\% prata) com $3 \mathrm{~mm}$ de comprimento foram colocados em contato com solução de $3 \mathrm{~mol} / \mathrm{L}$ de ácido nítrico e agitados em banho de água com $70^{\circ} \mathrm{C}$. Os núcleos foram, então, limpos duas vezes com água destilada em temperatura ambiente por 1 minuto num banho ultrassônico. A água é então drenada e etanol foi adicionado para facilitar a secagem. Uma solução de fosfato de sódio $(0,68 \mathrm{~g} / 10 \mathrm{~mL})$, oxalato de sódio $(0,56 \mathrm{~g} / 10 \mathrm{~mL})$, carbonato de sódio $(0,44 \mathrm{~g} / 10 \mathrm{~mL})$, azida de sódio $(0,27 \mathrm{~g} / 10 \mathrm{~mL})$ ou arsenato de sódio $(1,30 \mathrm{~g} / \mathrm{mL})$ foi adicionada em um frasco com 10 núcleos de prata e agitadas com 200 rpm por 62 horas. Os autores também relatam que pode se adicionar $50 \mu \mathrm{L}$ de solução de $30 \%$ de peróxido de hidrogênio para facilitar a oxidação. Os núcleos foram lavados com água e acetona;

- Exemplo 3: Núcleos de 99\% pura prata com $3 \mathrm{~mm}$ de comprimento foram colocados em contato com solução de $1 \mathrm{~mL}$ de $1 \mathrm{~mol} / \mathrm{L}$ de clorato de sódio e $9 \mathrm{~mL}$ de $1 \mathrm{~mol} / \mathrm{L}$ de ácido clorídrico e agitados com $200 \mathrm{rpm}$ por 62 horas. Os núcleos foram lavados com água e acetona. 
A parte 3 apresenta a metodologia para a fixação radioativa: Os núcleos preparados foram colocados em contato com a solução da parte 1 por 24 horas e agitados com 200 rpm. Os autores não relatam a eficiência do processo.

Como o tratamento superficial influencia na eficiencia de fixação, Lee et al publicaram o artigo "Surface teratments of silver rods with enhanced iodide adsorption for I-125 brachytherapy seeds" [44]. Vários ligantes, tratamentos abrasivos e compostos oxidantes foram testados. Os melhores foram: ligante fosfato (0,417 mol/L), ácido nítrico como abrasivo e peróxido de hidrogênio $(0,063 \mathrm{~mol} / \mathrm{L})$ como oxidante .

\subsection{Sementes de iodo-125 encontradas no mercado}

A seguir são apresentados os modelos de alguns fabricantes, destacando 0 processo de deposição do material radioativo. Alguns destes modelos não são mais fabricados.

- Eckert \& Ziegler - Bebig GmbH (Alemanha) IsoSeed® I25.S06 (solta),

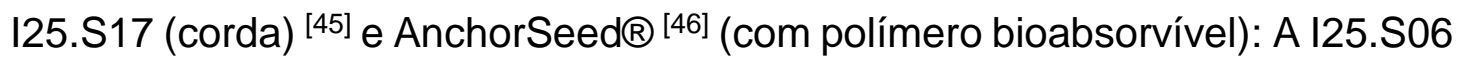
consiste em uma cápsula de titânio selada a laser, contendo no seu interior fio de ouro radiopaco, e uma camada de cerâmica com iodo-125. A I25.S17 contém um fio de prata com uma camada de $\mathrm{Ag}^{125}$ e um marcador. A AnchorSeed é o modelo I25.S17 envolvido por um polímero bioabsorvível que ajuda a fixar a semente ${ }^{[47]}$;

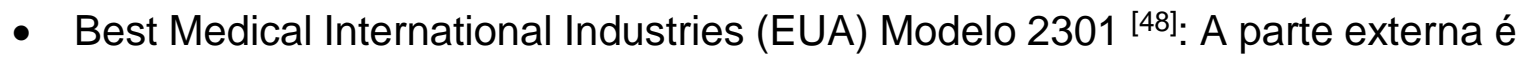
composta por um revestimento duplamente encapsulado de titânio, sem especificação do tipo de soldagem. O interior acomoda um marcador de tungstênio e o iodo-125 fixado em um substrato não especificado ${ }^{[4]}$;

- BARD - SourceTech Medical (EUA) BrachySource STM I125 [49]: A parte interna tem um fio de ouro como marcador, uma camada de alumínio e um "coating" de cobre. O iodo-125 é depositado num cilindro de alumínio com um núcleo de ouro e com uma camada de níquel ${ }^{[47]}$; 
- GE - Amersham (EUA) OncoSeed 6711 e 6702: O modelo 6711 possui núcleo de prata radiopaco, onde o iodo-125 está fixado e envolvido por cápsula de titânio, com selagem a laser. Já o 6702 apresenta o iodo-125 fixado por troca iônica em bolinhas de resina. A cápsula externa é de titânio, com selagem a laser ${ }^{[47]}$

\subsection{A Produção de Fontes no Brasil}

A classe médica, representada por médicos e físicos da área de radioterapia de diversos hospitais, repassou ao IPEN a necessidade de produção das sementes de iodo-125 no Brasil. A estimativa de demanda das sementes de iodo-125 é de 8.000 sementes/mês. A maioria dos fabricantes de sementes estão nos Estados Unidos. Cada processo de manufatura é único e protegido por patentes. A reprodução do método se torna inviável devido aos altos royalties que devem ser pagos.

Por essa razão, a pesquisadora Maria Elisa Chuery Martins Rostelato desenvolveu durante os anos 1999-2005 sua tese de doutorado "Estudo e Desenvolvimento de uma Nova Metodologia para Confecção de Sementes de iodo-125 para Aplicação em Braquiterapia" [15]. O projeto tinha como objetivo, além de realizar um extenso levantamento bibliográfico, o desenvolvimento de um protótipo que viabilizasse a produção local. Por se tratar de nova tecnologia o país está isento do pagamento de "royalties". O domínio tecnológico permitirá que as sementes produzidas localmente tenham menor custo possibilitando maior acesso ao tratamento. $O$ trabalho contemplou várias questões que foram abordadas por outros pesquisadores da equipe em diversas publicações.

O processo de soldagem da semente foi estudada e desenvolvida pelo tecnólogo Anselmo Feher. No ano de 2006, foi publicada sua dissertação de mestrado "Desenvolvimento de Procedimento Utilizando Processo de Soldagem Plasma para Confecção de Sementes de ${ }^{125}{ }^{[50]}$. Porém, como a soldagem à laser é mais rápida e eficiente, o mesmo pesquisador estudou e implementou o processo apresentado na sua tese "Estudo e desenvolvimento de um sistema de soldagem a laser Nd:YAG para produção de sementes de iodo-125 utilizadas em braquiterapia" [51].

A dosimetria da semente foi estudada pelo engenheiro químico Carlos Alberto Zeituni. Em 2008, foi publicada sua tese "Dosimetria de Fontes de lodo-125 Aplicadas em Braquiterapia" [52]. Este trabalho desenvolveu metodologia para os procedimentos de dosimetria. Novos métodos de dosimetria continuam sendo testados para 
comparação. Em 2011 o físico Eduardo Moura apresentou sua dissertação "Estudo e levantamento de parâmetros para dosimetria de fontes de iodo-125 aplicadas em braquiterapia" [53] que deu continuação aos estudos do Dr. Zeituni e definiu alguns parâmetros segundo 0 "Dosimetry of interstitial brachytherapy sources: recomendations of the AAPM Radiation Therapy Committee Task Group No. 43" [54].

O controle de qualidade foi estudado pelo tecnólogo João A. Moura. Sua dissertação apresentada em 2009 com o título "Estudo e desenvolvimento de metodologia para controle de qualidade em processo de produção de fontes seladas de lodo-125 para aplicação em braquiterapia" [55] definiu o método mais eficiente para realizar os testes de vazamento das sementes, seguindo a "International Organization for Standardization: Radiation protection - Sealed radioactive sources - Leakage test methods" [56]. João também apresentou o processo de automação dos testes de estaqueidade em seu doutorado intitulado "Desenvolvimento e Construção de Sistema Automatizado para Controle de Qualidade na Produção de Sementes de lodo-125" [57].

Devido à pequena dimensão da semente, o sistema de soldagem deve ser automatizado e ter alta precisão. Em 2010, o tecnólogo Samir Somessari apresentou sua dissertação de mestrado com o título "Automação do processo de soldagem a laser (Nd:YAG) para confecção das sementes de iodo-125 utilizadas em braquiterapia" [58].

Em 2012 a física médica Carla Daruich de Souza apresentou sua dissertação com título "Comparação entre métodos de fixação do iodo radioativo em substrato de prata para confecção de fontes utilizadas em Braquiterapia" [8]. A autora comparou quatro métodos de deposição em prata utilizando iodo-131 incluindo um inédito, desenvolvido em parceria com o Instituto de Química da USP. Neste novo método, os núcleos de prata foram tratados durante 5 minutos com solução de piranha (peróxido de hidrogênio a 35\% e ácido sulfúrico a 95\% na proporção volumétrica de $3 / 4$ de peróxido para $1 / 4$ de ácido sulfúrico). A solução radioativa de $10 \mathrm{mCi}$ com 10 núcleos tratados foi separada e preparada da seguinte maneira: 1/3 do volume total da solução ativa de iodeto de sódio $(130 \mu \mathrm{L})$ foi misturado com uma gota $(0,10 \mu \mathrm{L})$ de solução de borohidreto de sódio $(0,26 \mathrm{~mol} / \mathrm{L})$. Logo em seguida, $0,15 \mu \mathrm{L}$ de ácido acético $2 \mathrm{~mol} / \mathrm{L}$ foi acrescentado, com a finalidade de parar a reação da solução radioativa com o borohidreto de sódio. Nos 2/3 restantes da solução radioativa foram acrescentados $303 \mu \mathrm{L}$ de ácido acético $2 \mathrm{~mol} / \mathrm{L}$. O tempo de reação 
foi de 5 horas resultando numa eficiência de fixação, de $99,83 \% \pm 3,30 \%$. Buscou-se o maior valor de fixação possível com a finalidade de minizar rejeitos e o custo final do produto (o iodo radioativo representa mais de $90 \%$ do custo da semente).

O físico Osvaldo Luiz da Costa irradiou Xenônio-124 para a produção do lodo-125 no reator IEA-R1 do IPEN. Sua tese "Estudo e desenvolvimento de uma nova metodologia de produção de iodo-125 a partir de xenônio-124 pelo método de ativação neutrônica" [59] apresentada em 2015 é de extrema importância para que o grupo controle a fabricação do iodo-125 e reduza ainda mais o custo final da semente.

A física médica Bruna Teiga Rodrigues estudou núcleos poliméricos na sua dissertação apresentada em 2015 com o título "Estudo e desenvolvimento de metodologia para fixação de iodo radioativo em substrato polimérico para confecção de fontes utilizadas em braquiterapia" ${ }^{[60]}$. O iodo-125 adere 99\% em resina epóxi e permanece totalmente estanque. A fonte é moldável facilmente com molde de silicone.

O químico Fernando dos Santos Peleias Junior desenvolveu em seu projeto de mestrado [61] uma metodologia de síntese do Poli(ácido láctico-co-ácido glicólico) (PLGA), utilizado na fabricação de uma corda polimérica que envolve a semente de iodo-125 (forma mais utilizada pelos médicos brasileiros). O método tradicional envolve a utilização dos dímeros L-lactídeo e glicolídeo, encarecendo significativamente o processo. Adicionalmente, também é proposto a utilização de um iniciador alternativo de zircônio em vez do tradicional octanoato de estanho. Compostos de zircônio são, em geral, cerca de 10 a 20 vezes menos tóxicos do que os de estanho ${ }^{[62]}$. O aluno continua a pesquisa no doutorado.

\subsection{Características do iodo e do iodo-125}

O átomo iodo foi descoberto acidentalmente em 1811 pelo químico Barnard Courtois quando ele adicionou ácido sulfúrico $\left(\mathrm{H}_{2} \mathrm{SO}_{4}\right)$ em excesso à cinza de alga marinha para extrair compostos de sódio e potássio. Um gás violeta saiu do experimento condensando-se em objetos de metal no seu laboratório. Após análise do sólido criado, o novo átomo descoberto recebeu o nome de iodo, inspirado no nome grego para cor violeta, iodes [63]. A ligação com seu uso pela tiroide foi feita alguns anos depois. Em 8 anos da descoberta, o iodo já era utilizado efetivamente no tratamento da gota [64]. 
Quando iodo entra na circulação sanguínea, a tiroide o absorve para síntese de seus hormônios. A soma não absorvida é excretada pela urina [65]. Adultos saudáveis possuem cerca de $15-20 \mathrm{mg}$ de iodo no corpo, sendo que $70 \%-80 \%$ está na tiroide. ${ }^{[6]} \mathrm{A}$ tabela 2 apresenta características físico-químicas do iodo elementar. [63, 64]

Tabela 2: Características do lodo. [67]

\begin{tabular}{|c|c|}
\hline Número Atômico & 53 \\
\hline Massa Atômica & 126,90447 \\
\hline Ponto de Fusão & $386,85 \mathrm{~K}$ \\
\hline Ponto de ebulição & $457,55 \mathrm{~K}$ \\
\hline Densidade & $4,93^{\mathrm{g}} / \mathrm{cm}^{3}$ \\
\hline Fase à temperatura ambiente & Sólido \\
\hline Classificação & Não metal, Halogênio \\
\hline Energia de ionização & $10,45 \mathrm{eV}$ \\
\hline Estados de Oxidação & $+7,+5,+1,-1$ \\
\hline Configuração Eletrônica & $\begin{array}{c}1 s^{2} \quad 2 s^{2} \quad 2 p^{6} \quad 3 s^{2} \quad 3 p^{6} \quad 3 d^{10} \\
4 s^{2} \quad 4 p^{6} \quad 4 d^{10} \quad 5 s^{2} \quad 5 p^{5}\end{array}$ \\
\hline Posição na tabela periódica & Período: 5 Grupo: 17 \\
\hline
\end{tabular}

Do ponto de vista químico, o iodo é um halogênio (estrutura similar ao cloro e flúor). Halogênios são altamente reativos pois são muito eletronegativos. Eles possuem sete elétrons de valência no nível de energia mais distante, o que significa que eles podem ganhar elétrons de outros elementos para satisfazer a regra do octeto [68].

A espécie iônica do iodo, o iodeto (I-), forma após a oxidação uma molécula diatômica, $I_{2(g)}$, com ligações covalentes. Essas moléculas são agrupadas por forças intermoleculares fracas conhecidas como forças de dispersão do tipo van der WallsLondon ${ }^{[69]}$.

Isótopos radioativos do iodo são amplamente utilizados na medicina. Suas massas atômica variam entre 107 até $145 \mathrm{u}$ com diferentes tipos de decaimento e meias-vida. Para descrição completa veja referência do "Nuclear Data Center" [70]. 
O iodo-125 é produzido em reator nuclear irradiando o gás xenônio $(\mathrm{Xe})$ natural contendo $0.0965 \%{ }^{124} \mathrm{Xe}$. Os nêutrons atingem o núcleo ${ }^{124} \mathrm{Xe}$ transformando-o para ${ }^{125} \mathrm{Xe}$ que decai para ${ }^{125}$. Para a purificação, o frasco de irradiação é congelado a $-15^{\circ} \mathrm{C}$ separando o iodo do xenônio que não reagiu. Uma solução de $\mathrm{NaOH}$ é utilizada para lavar o frasco e coletar o iodo. Uma coluna de troca de cátions troca contaminantes indesejáveis como ${ }^{137 / 134} \mathrm{Cs}^{+}$(íon césio) por outros não radioativos [71]. O iodo-125 decai por captura eletrônica para o telúrio-125. Fótons de 25,2 keV, $22,1 \mathrm{keV}$ e 35,5 keV (média de $29 \mathrm{keV}$ ), são emitidos. Em virtude da baixa energia média de emissão, seus fótons têm pouco poder de penetração. Sua meia-vida é de 59,43 dias ${ }^{[72]}$.

\subsection{Diagrama esquemático da semente}

O iodo-125 é fixado num núcleo de prata de $3 \mathrm{~mm}$ de comprimento e $0,50 \mathrm{~mm}$ de diâmetro que é posicionado no interior de tubos de titânio de $0,80 \mathrm{~mm}$ de diâmetro externo, 0,05 $\mathrm{mm}$ e espessura de parede e $4,50 \mathrm{~mm}$ de comprimento (Figura 2). A prata também é usada como marcador nos exames de imagem.

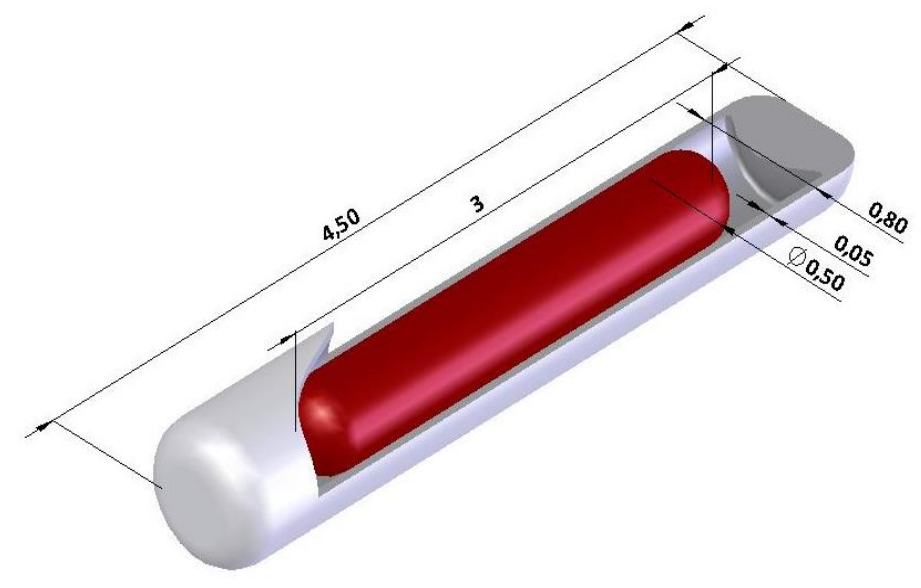

Figura 2: Desenho esquemático da semente (dimensões em mm).

\subsection{Radioquímica}

Em pesquisas com radioisótopos, a medida Atividade (A) é geralmente mais importante que concentração química. Na maioria das vezes, cálculos de eficiência 
são realizados por meio da medida da atividade final e inicial do experimento. É possível converter atividade em concentração e massa seguindo as equações 1-4:

$$
\begin{gathered}
A=\lambda \cdot N \\
\lambda=\frac{\ln 2}{T_{\frac{1}{2}}} \\
\text { mols }_{\text {amostra }}=\frac{N}{N_{a}} \\
\operatorname{massa}_{\text {amostra }}(g)=\frac{M W x N}{N_{a}}
\end{gathered}
$$

$T_{\frac{1}{2}}=$ meia-vida (s)

$A=$ atividade em Becquerel (decaimentos/segundo)

$\lambda=$ constante de decaimento $\left(\mathrm{s}^{-1}\right)$

$M W=$ massa atômica

$N_{a}=$ número de avogadro $\approx 6.02 \times 10^{23}$

Por exemplo, em um tratamento de câncer de tiroide com iodo-131, administrase a atividade de 5,55-7,40 GBq (150-200 mCi). Convertendo:

$$
\begin{aligned}
& \lambda=\frac{\ln 2}{T_{\frac{1}{2}}}=\frac{\ln 2}{8,02 d \times 24 h \times 3600}=10^{-6} \mathrm{~s}^{-1} \\
& A=\lambda \cdot N \rightarrow N=\frac{A}{\lambda}=\frac{7,40 \times 10^{9}}{10^{-6}}=7,40 \times 10^{15} \text { átomos } \\
& \text { mass }_{\text {amostra }}(\mathrm{g})=\frac{M W \times N}{N_{a}}=\frac{131 \times 7,40 \times 10^{15}}{6,02 \times 10^{23}}=1,61 \cdot 10^{-6} \mathrm{~g}
\end{aligned}
$$

Pequenas massas como as calculadas acima, levam à resultados imprevisíveis. De acordo com Karl-Heinz Neeb "A radioquímica é um ramo da química, mas é possível encontrar em seu contexto várias características de uma disciplina autônoma. Na verdade, radionuclídeos obedecem às mesmas regras que 
seu(s) isótopo(s) não radioativo(s); apesar de existirem aspectos adicionais que tem que ser considerados... Como exemplo, concentrações de produtos de fissão em soluções aquosas medidas durante a operação normal de reatores e em acidentes usualmente estão em mínimas quantidades, cerca de $10^{-9} \mathrm{~mol} / \mathrm{L}$, apesar de este valor corresponder a níveis altíssimos de atividade radioativa. Com massas tão pequenas, muitos elementos apresentam um comportamento anômalo. Portanto, é improvável que as reações químicas esperadas ocorram nessas concentrações ínfimas". ${ }^{\text {[73] Este }}$ "princípio" deve ser sempre considerado no estudo de reações químicas envolvendo radioisótopos, principalmente os "iodos" $\left(I^{125}\right.$ e $\left.{ }^{131}\right)$ radioativos. O experimento pode não seguir o caminho esperado, visto que uma simples impureza pode alterar a reação. Por essa razão, tópicos de interesse, como concentração final, $\mathrm{pH}$ e exposição à luz, devem ser investigados nas condições dos experimentos que estão sendo estudados. Além disso, o sistema de segurança do local deve ser rigoroso e periodicamente avaliado. 


\section{METODOLOGIA E RESULTADOS}

Nesta sessão serão apresentadas as novas metodologias de fixação do iodeto radioativo no núcleo de prata, a análise das modificações feitas pelo pré-tratamento na superfície e a discussão de alguns itens considerados importantes durante 0 desenvolvimento do trabalho.

De maneira genérica, a rota química da maioria das metodologias na literatura segue o caminho indireto de troca de íons:

$$
\begin{gathered}
A g^{0} \underset{\text { oxida }}{\longrightarrow} A g^{+}+e^{-} \text {E=-0,80 V } \\
x A g^{+}+A^{x-} \rightarrow A g_{x} A \\
\text { A sendo um ânion qualquer } \\
A g_{x} A+I^{-} \rightarrow A g I+x A \text { ou } A_{x}
\end{gathered}
$$

A rota direta, pouco explorada devido a baixas eficiênicas, segue a equação:

$$
A g^{0} \underset{\text { oxida }}{\longrightarrow} A g^{+}+I^{-} \longrightarrow A g I
$$

Após a reação química, cada núcleo de prata tem a radioatividade aferida. Com a soma dos valores é possível realizar o cálculo de porcentagem de fixação, que reperesenta a eficiência do método estudado.

\subsection{Cálculo da eficiência de medição}

Dois procedimentos para realização do cálculo de eficiência foram encontrados na literatura e nomeados neste texto como método da alíquota e da comparação. Dependendo da maneira adotada, é possível encontrar resultados completamente diferentes.

\section{Método da alíquota}

Este método é o mais utilizado pelos pesquisadores. Ele consiste em retirar uma alíquota da solução radioativa completa no início do experimento e aferir a atividade radioativa. Decorrido o tempo do experimento, a mesma quantidade é medida novamente. A diferença das medidas entre ambas alíquotas é considerada 
igual a atividade fixada nos núcleos de prata. Por exemplo, considera-se uma reação com 10 núcleos de prata em uma solução de $10 \mathrm{~mL}$ com $10 \mathrm{mCi} / \mathrm{mL}$. Com uma pipeta automática, $1 \mathrm{~mL}$ da solução é pipetada e a atividade medida será $\approx 1 \mathrm{mCi}$. Após decorrido o tempo da reação, a mesma quantidade é medida novamente. Supondo uma atividade de $0,20 \mathrm{mCi}$, presume-se $80 \%$ de fixação nos núcleos. Este método não considera a perda de material, assumindo que toda atividade que não está presente na solução está fixada nos núcleos. E como os núcleos em si não são medidos, não é possível garantir o valor de eficiência. A fórmula utilizada para 0 cálculo é:

$$
\text { Fixação total }_{\%}=-\left(\text { Ativ.aliq. final }^{-} \text {Ativ } \cdot \text { aliq inicial }\right) * 100
$$

\section{Método da Comparação}

As medições de atividade e a posterior comparação entre valores não tem condições ideais de medição. O experimento é montado num frasco, selado e tem a atividade mensurada (medida 1) numa câmara de ionização. Após 24 horas, o mesmo frasco é medido antes de ser aberto (medida 2). Essas duas medidas são comparáveis, pois são feitas da mesma maneira com o mesmo frasco. Após a medida, o frasco é aberto e os núcleos de prata secados em papel de filtro. Depois são colocados em forma de papel ou algum tipo de tubo e posicionados no detector. A atividade radioativa dos dez núcleos é somada (medida 3) e a eficiência é calculada através da comparação da medida 1 com a medida 3 . Essa comparação não pode ser considerada totalmente válida, pois os materiais são completamente diferentes. A absorção da radioatividade nas paredes do vidro é diferente na forma de papel. Além disso, não é possível comparar um substrato líquido com um sólido. Porém, não foram encontradas maneiras melhores de se realizar as medições. Neste trabalho, os cálculos de eficiência foram realizados por essa metodologia. As medidas foram realizadas em detectores tipo poço da marca Carpintec 15R. A fórmula utilizada para o cálculo é:

$$
\text { Fixação } \text { total }_{\%}=\frac{\text { Medida }_{3}}{\text { Medida }_{1}} * 100
$$

\subsection{Metodologia dos experimentos}

Novos métodos de fixação do iodo-125 na superfície da prata foram estudados e desenvolvidos. Foram consideradas a reprodutibilidade e a facilidade de 
implementação no novo laboratório de sementes do IPEN. Como se trata de uma nova metodologia, uma patente foi requerida com os resultados finais.

O núcleo de prata é comprado da empresa Cenabrás já cortado em secções de $3 \mathrm{~mm}$. A composição é 99,99\% prata. Porém, a prata, por ter um alto potencial de oxidação, em contato com o ar forma facilmente óxido de prata $\mathrm{Ag}_{2} \mathrm{O}$. O óxido de prata possui solubilidade em água de $0,0025 \mathrm{~g} / 100 \mathrm{~mL}$ e geometria cúbica, que é altamente estável [74]. Portanto, para que a deposição de iodeto ocorra com alta eficiência é necessário decapar a superfície ou depositar outro composto que faça a troca iônica com o iodeto.

A solução radioativa de iodo se encontra na forma de iodeto de sódio $\left(\mathrm{Na}^{125} \mathrm{l}\right)$ com pH 12. A solução é adquirida com $70 \mathrm{mCi}$ em volumes pequenos (cerca de $0,20 \mathrm{~mL}$ ). O procedimento padrão adotado é a utilização de uma seringa de vidro micrograduada para a retirada do material na quantidade calculada. Por exemplo, em experimento com três núcleos, $3 \mathrm{mCi}$ são necessários. Aproximadamente, $10 \mu \mathrm{L}$ são coletados para o experimento. $\mathrm{O}$ volume final é completado com água ou outra solução desejada. O procedimento é alterado de acordo com as condições de fornecimento. $\mathrm{O} \mathrm{Na}^{125}$ é totalmente solúvel nas condições do experimento (solubilidade do iodeto de sódio em água $184 \mathrm{~g} / 100 \mathrm{~mL}$ em $25^{\circ} \mathrm{C}$ com pH entre 8-9,5).

A primeira investigação realizada foi um experimento sem o acréscimo de nenhuma solução e nenhuma modificação na superfície do núcleo de prata. A eficiência atingida foi de apenas $\approx 4 \%$ da atividade total utilizada (Tabela 3 ) comprovando a necessidade de intervenção.

Tabela 3: Resultados de experimento realizado com núcleos de prata sem nenhum pré-tratamento (mantendo as quantidades do método 2).

\begin{tabular}{cc}
\hline Ativ. Total $(\mathbf{m C i})$ & $\mathbf{3 , 1 0}$ \\
\hline Ativ. em $\mathbf{2 4 h}(\mathbf{m C i})$ & 2,24 \\
Núcleo $\mathbf{1}(\mathbf{m C i})$ & 0,05 \\
Núcleo $\mathbf{2}(\mathbf{m C i})$ & 0,03 \\
Núcleo $\mathbf{3}(\mathbf{m C i})$ & 0,04 \\
Total $(\mathbf{m C i})$ & 0,12 \\
Desvio & 0,01 \\
\% de eficiência & 3,90 \\
\hline
\end{tabular}




\section{MÉTODO 1}

Decapagem com solução piranha e nitrato de ferro (III) como oxidante

Parceria com o Instituto de Química da USP

Ferro(III) é um agente oxidante relativamente forte $\left(\mathrm{E}^{0}=0,77 \mathrm{~V}\right)$ apresentando potencial redução similar ao par $\mathrm{Ag}^{+} / \mathrm{Ag}\left(\mathrm{E}^{0}=0,80 \mathrm{~V}\right){ }^{[75]}$. O $\mathrm{Fe}(\mathrm{III})$ oxida a prata metálica a $\mathrm{Ag}^{+}$que posteriormente reage com 0 íon $\mathrm{I}^{-}$formando $\circ \mathrm{Ag}^{125}$ para a produção dos núcleos radioativos ${ }^{[75]}$.

Em um experimento típico, $0,02 \mathrm{~g}$ de nitrato férrico foram dissolvidos em ácido sulfúrico $(3,30 \mathrm{M}, 100 \mu \mathrm{L})$ e $20 \mu \mathrm{L}$ de água destilada. Três núcleos pré-tratados com a solução piranha (peróxido de hidrogênio a $35 \%$ e ácido sulfúrico a $95 \%$ na proporção volumétrica de $3 / 4$ de peróxido para $1 / 4$ de ácido sulfúrico) foram inseridos no frasco. Dez microlitros de solução de iodo radioativa com $\approx 1 \mathrm{mCi} /$ núcleo foi adicionada ao frasco. A reação permaneceu sob agitação por $24 \mathrm{~h}$. $\mathrm{O}$ volme final foi mantido em $150 \mu \mathrm{L}$. Os resultados estão na tabela 4.

Tabela 4: Resultados experimento 1.

\begin{tabular}{cccc}
\hline & Experimento 1 & Experimento 2 & Experimento 3 \\
\hline Ativ. Total $(\mathbf{m C i})$ & 2,78 & 3,00 & 3,00 \\
Ativ. em 24h $(\mathbf{m C i})$ & 1,13 & 1,34 & 1,64 \\
Núcleo 1 $(\mathbf{m C i})$ & 0,57 & 0,30 & 0,28 \\
Núcleo 2 (mCi) & 0,34 & 0,37 & 0,47 \\
Núcleo 3 (mCi) & 0,41 & 0,35 & 0,21 \\
Total $(\mathbf{m C i})$ & 1,32 & 1,02 & 0,96 \\
Desvio & 90,20 & 25,14 & 99,05 \\
\% de eficiência & $47,33 \%$ & $34,00 \%$ & $32,00 \%$ \\
\hline Total global & & $37,76 \%$ & \\
\hline
\end{tabular}

\section{MÉTODO 2}

Deposição utilizando íons de enxofre

A semente líder de mercado no tratamento do câncer de próstata possui núcleo de prata escurecido ${ }^{[15]}$. Essa característica inspirou o estudo e desenvolvimento do 
presente método. Sabe-se que após contato prolongado, o talco comum pode provocar o escurecimento da prata. Então, utilizou-se um talco facilmente encontrado no mercado de composição: ácido benzoico - 0,352 g, enxofre - 17,602 g, ácido bórico - 11,735 g, óxido de zinco - 11,735 g, amido - 23,470 g, talco tipo Veneza (contém silicato de magnésio - $3 \mathrm{MgO}^{*} 4 \mathrm{SiO}_{2}{ }^{*} \mathrm{H}_{2} \mathrm{O}$ ) qsp $100 \mathrm{~g}$ com pH neutro quando dissolvido em água. Este talco foi colocado em um frasco e ficou em contato com os núcleos de prata por uma semana. Os núcleos ficaram totalmente escurecidos o que pode indicar reação com enxofre. Os íons de enxofre livres podem formar diversos sais com a prata (tabela 5).

Tabela 5: Ânions de enxofre; Sais de prata formados com ânion de enxofre [76].

\begin{tabular}{ccc}
\hline Ânion & Fórmula do sal & Nome \\
\hline $\mathbf{S}^{2-}$ & $\mathrm{Ag}_{2} \mathrm{~S}$ & Sulfeto de prata \\
$\mathbf{S O}_{4}{ }^{2-}$ & $\mathrm{Ag}_{2} \mathrm{SO}_{4}$ & Sulfato de prata \\
$\mathrm{SO}_{3}{ }^{2-}$ & $\mathrm{Ag}_{2} \mathrm{SO}_{3}$ & Sulfito de prata \\
$\mathbf{S C N}^{-}$ & $\mathrm{AgSCN}^{2}$ & Tiocianato de prata \\
$\mathrm{S}_{2} \mathrm{O}_{3}{ }^{2-}$ & $\mathrm{Ag}_{2} \mathrm{~S}_{2} \mathrm{O}_{3}$ & Tiossulfato de prata \\
$\mathbf{S}_{2} \mathrm{O}_{4}{ }^{2-}$ & $\mathrm{Ag}_{2} \mathrm{~S}_{2} \mathrm{O}_{4}$ & Hipossulfito de prata \\
$\mathbf{S}_{2} \mathrm{O}_{8}{ }^{2-}$ & $\mathrm{Ag}_{2} \mathrm{~S}_{2} \mathrm{O}_{8}$ & Persulfato de prata \\
$\mathbf{S}_{4} \mathrm{O}_{6}{ }^{2-}$ & $\mathrm{Ag}_{2} \mathrm{~S}_{4} \mathrm{O}_{6}$ & Tetrationato de prata \\
\hline
\end{tabular}

O íon tiossulfato, $\mathrm{S}_{2} \mathrm{O}_{3}{ }^{2-}$, é altamente utilizado para escurecer a prata durante o processo de pátina (conhecido como "liver of suphur").[77] Para confecção de peças de prata com desenhos em partes escurecidas, utiliza-se a troca tiossulfato-iodeto mostrada nas reações [78]:

$$
\begin{gathered}
2 \mathrm{Ag}^{+}+\mathrm{S}_{2} \mathrm{O}_{3}{ }^{2-} \rightarrow \mathrm{Ag}_{2}\left(\mathrm{~S}_{2} \mathrm{O}_{3}\right) \\
\mathrm{Ag}_{2}\left(\mathrm{~S}_{2} \mathrm{O}_{3}\right)+2 I^{-} \rightarrow 2 \mathrm{AgI}+\mathrm{S}_{2} \mathrm{O}_{3}{ }^{2-}
\end{gathered}
$$

O íon tiossulfato pode ser formado pelo talco por reações entre o enxofre e o oxigênio do ar. O ácido bórico e óxido de zinco são largamente utilizados por joalheiros para remover o óxido de prata. $O$ ácido benzoico auxilia na conversão de óxido de prata à prata metálica [79]. O talco utilizado neste método é barato e 
facilmente encontrado (em torno de $R \$ 10,00 / 200 \mathrm{~g}$ ). Em um frasco de com aproximadamente 20 gramas de material, 1000 núcleos são facilmente pré-tratados.

A fim de testar a hipótese do tiossulfato, três variações da metodologia do talco foram executadas:

- Variação 1: Deposição utilizando talco;

- Variação 2: Deposição utilizando uma mistura de talco com tiossulfato de sódio (50\% em massa de talco);

- Variação 3: Deposição utilizando somente o tiossulfato de sódio.

Os núcleos utilizados nos testes ficaram em contato com seus respectivos tratamentos por dois meses antes da utilização. A eficiência da reação permaneceu a mesma com núcleos que permaneceram dois anos em contato. Os núcleos só são retirados momentos antes do experimento e lavados rapidamente com água destilada. Em um experimento típico, $140 \mu \mathrm{L}$ de água foram misturados com $10 \mu \mathrm{L}$ (utilizado direto sem diluição) de solução de iodo radioativa com $\approx 1 \mathrm{mCi} /$ núcleo. Três núcleos pré-tratados foram inseridos no frasco e reagiram durante $24 \mathrm{~h}$. Os resultados estão apresentados na tabela 6.

Tabela 6: Resultados método 2.

\begin{tabular}{|c|ccc|ccc|ccc|}
\hline & \multicolumn{3}{|c|}{ Variação 3 } & \multicolumn{3}{c|}{ Variação 2 } & \multicolumn{3}{c}{ Variação 1 } \\
\hline Ativ. Total & 3,04 & 3 & 3,49 & 3,61 & 3,13 & 3,00 & 4,15 & 3,95 & 2,63 \\
\hline Ativ. em 24h (mCi) & 1,58 & 1,34 & 1,85 & 2,18 & 2,20 & 2,31 & 3,51 & 3,15 & 2,18 \\
\hline Núcleo 1 $(\mathbf{m C i})$ & 0,86 & 0,77 & 0,93 & 0,62 & 0,78 & 0,48 & 0,30 & 0,16 & 0,18 \\
\hline Núcleo 2 (mCi) & 0,79 & 0,60 & 0,72 & 0,93 & 0,42 & 0,62 & 0,29 & 0,17 & 0,24 \\
Núcleo 3 (mCi) & 0,66 & 0,61 & 0,90 & 0,57 & 0,39 & 0,42 & 0,27 & 0,17 & 0,22 \\
\hline Total (mCi) & 2,31 & 1,97 & 2,55 & 2,12 & 1,59 & 1,52 & 0,86 & 0,51 & 0,63 \\
Desvio & 0,07 & 0,07 & 0,08 & 0,15 & 0,17 & 0,08 & 0,01 & 0,01 & 0,02 \\
\% de eficiência & 76,12 & 65,84 & 73,15 & 58,83 & 50,77 & 50,57 & 20,77 & 12,73 & 23,99 \\
\hline Total global & \multicolumn{3}{|c|}{$71,70 \%$} & \multicolumn{3}{c}{$53,39 \%$} \\
\hline
\end{tabular}

\subsection{Parâmetros estudados}

Esta sessão discutirá tópicos considerados importantes na execução do trabalho. 


\subsubsection{Foto-sensibilidade}

Halogenetos de prata $(\mathrm{AgX}, \mathrm{X}=\mathrm{Cl}, \mathrm{Br}, \mathrm{l})$ são materiais extremamente fotossensíveis amplamente utilizados em revelação fotográfica. Por absorver a luz incidente, os halogenetos de prata podem gerar elétrons na banda de condução e buracos na banda de valência. Os elétrons gerados são facilmente capturados por sítios $\mathrm{Ag}^{+}$que estejam disponíveis. Os buracos fotogerados oxidam a superfície libertando $\mathrm{X}_{2}$, resultando na fotodecomposição de halogenetos de prata e a formação de Ag metálica. ${ }^{[80]}$ Segundo a teoria, para evitar que os íons I' se oxidem formando $\mathrm{I}_{2}$, a reação de fixação do iodeto na superfície da prata deve ser realizada na mínima presença de luz.

A influência da luz foi testada com a método 2 variação 1 . O experimento seguiu exatamente os passos apresentados, com a diferença quantidade de luz ser a mínima possível. O resultado (tabela 7) mostra pouca diferença. Devido ao tamanho diminuto do núcleo de prata, deve-se priorizar a segurança e realizar o experimento na presença de luz.

Tabela 7: Resultados do método 2 variação 1 realizado na presença e ausência de luz.

\begin{tabular}{ccc}
\hline & Com luz & Sem luz \\
\hline Ativ. Total & 4,15 & 3,00 \\
\hline Ativ. em 24h $(\mathbf{m C i})$ & 3,51 & 2,80 \\
Núcleo 1 $\mathbf{( m C i )}$ & 0,30 & 0,20 \\
Núcleo 2 (mCi) & 0,29 & 0,21 \\
Núcleo 3 (mCi) & 0,27 & 0,37 \\
Total (mCi) & 0,86 & 0,78 \\
Desvio & 0,01 & 0,07 \\
\hline \% de eficiência & $20,77 \%$ & $26,03 \%$ \\
\hline
\end{tabular}

\subsection{2 "O iodo-131 tem o mesmo comportamento do iodo-125"}

Muitos pesquisadores fazem seus testes com o iodo-131 afirmando que por ambos "serem iodo" os resultados são comparáveis. A justificativa para tal substituição é a facilidade de produção do iodo-131. Durante o desenvolvimento do projeto "Comparação entre métodos de fixação do iodo radioativo em substrato de prata para confecção de fontes utilizadas em braquiterapia" [8] essa premissa foi utilizada, já que o iodo-131 é produzido pelo IPEN. O novo e melhor método, 
desenvolvido em parceria com o Instituto de Química da USP, obteve $99,83 \% \pm 3,30 \%$ de eficiência ${ }^{[8]}$.

Tentativas de adaptação deste e de outros métodos previamente desenvolvidos pelo grupo de braquiterapia do IPEN falharam (cerca de $80 \%$ menos fixação com o iodo-125). Sabe-se que as soluções dos dois "iodos" são feitas de maneiras completamente diferentes. A solução de iodo-131 feita pelo IPEN é borbulhada em hidróxido de sódio com pH 12 e possui cerca de 19\% de iodatos que são reconvertidos pela solução de borohidreto de sódio. Já a solução de iodo-125 importada pode ser feita de diferentes maneiras não informadas pelas empresas e possui foco na pureza radioquímica (e não química).

Além disso, a quantidade de iodo existente em cada solução é diferente. Partindo de uma solução de $1 \mathrm{mCi}$ têm-se:

- Para iodo-131: meia-vida 8,04 dias

$$
\begin{gathered}
A=\lambda \cdot N \\
10^{-3} \cdot 3,7 \cdot 10^{10}=\frac{\ln 2}{8,04 \cdot 24 \cdot 60 \cdot 60} \cdot N \\
N=3,70 \cdot 10^{13} \text { átomos em } 1 \mathrm{mCi} \\
m=8,06 \cdot 10^{-9} \mathrm{~g} \mathrm{em} 1 \mathrm{mCi}
\end{gathered}
$$

- Para iodo-125: meia-vida 59,43 dias

$$
\begin{gathered}
A=\lambda \cdot N \\
10^{-3} \cdot 3,7 \cdot 10^{10}=\frac{\ln 2}{60,14 \cdot 24 \cdot 60 \cdot 60} \cdot N \\
N=2,70 \cdot 10^{14} \text { átomos em } 1 \mathrm{mCi} \\
m=5,75 \cdot 10^{-8} \mathrm{~g} \mathrm{em} 1 \mathrm{mCi}
\end{gathered}
$$

Essa comparação indica que as proporções dos reagentes mudam para cada isótopo do iodo e os valores devem ser ajustados. As ínfimas massas calculadas indicam também que grande pureza química deve existir em todo curso do experimento. Por exemplo, $1 \%$ de impureza em $1 \mathrm{~g}$ de solução resulta em $0,01 \mathrm{~g}$ quantidade que é muito maior que o total de iodo radioativo. Essa é uma das razões pelas quais o comportamento radioativo do iodo é atípico e os experimentos não 
devem ser realizados com outros isótopos assumindo comportamento similar, já que eles são sintetizados por rotas diferentes e possuem contaminantes diferentes.

Além disso, o iodo-131 possui energia de emissão mais de 10 vezes maior que o iodo-125 (364 KeV e $29 \mathrm{KeV}$ respectivamente). Isso significa que a qualidade e precisão da medição da atividade realizada pela câmara de ionização é muito maior para o iodo-131 (o iodo-131 tem energia próxima da fonte de calibração de bário-133, 364 para $356 \mathrm{KeV}$, respectivamente. A eficiência de medição para o bário é muito alta, com apenas $1,78 \%$ de desvio. O desvio para o iodo-125 pode chegar a $45 \%$. Fonte: registro de calibração). Também deve-se considerar que a auto absorção da atividade radioativa do iodo-125 pela prata é cerca de $20 \%$ da atividade total na semente ${ }^{[13]}$.

\subsubsection{Tipo do frasco utilizado}

Diferentes resultados são obtidos de acordo com o frasco utilizado. Conforme o experimento realizado por Kennedy et. al. ${ }^{[81]}$, o tipo de frasco utilizado para a reação radioquímica é de extrema importância. A figura 3 , apresentada em [81], o melhor material para realizar estes experimentos foi o vidro. $O$ iodo atravessa com facilidade frascos de plástico.

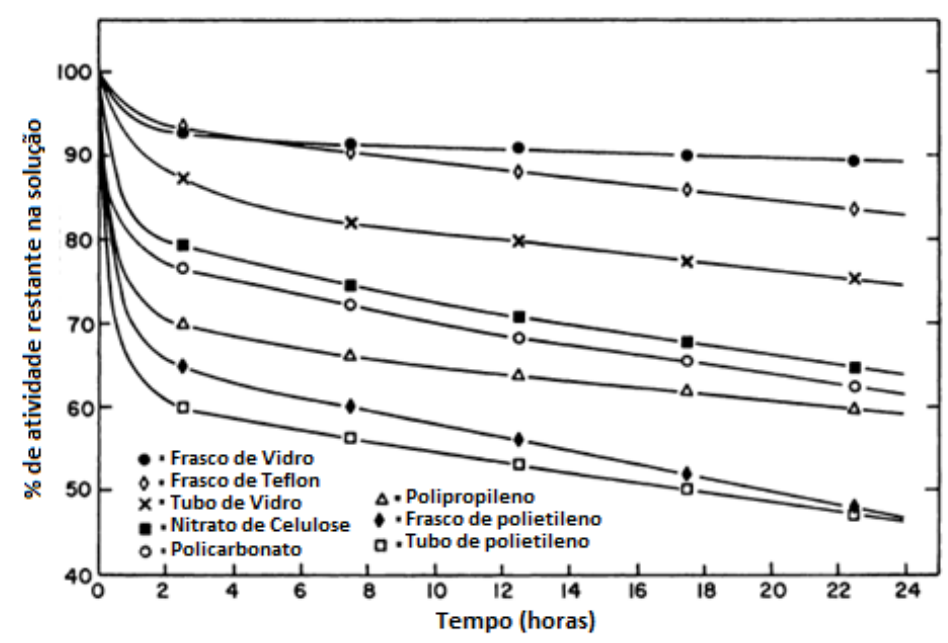

Figura 3: Porcentagem de ${ }^{131} \mid$ restantes em soluções armazenadas em frascos de diferentes materiais por hora. Apresentado em [81]. 
Para investigar a hipótese, realizou-se a reação de fixação radioativa em um capilar de vidro tipo pirex selado em ambas as pontas. Mesmo assim, 9,30\% de iodo-125 "atravessou" o frasco em 24 horas (frasco (a) tabela 8).

Experimentos foram realizados com iodo- $125 \mathrm{com}$ frascos de diversos tipos (figura 4). Os resultados estão apresentados na tabela 8. O frasco que apresentou maior estaqueidade foi o tipo (e).

Um experimento seguindo a seguindo o método 2 variação 1 realizado no frasco em que o iodo é comercializado (h) demonstrou (tabela 9) que cerca de $35 \%$ de atividade é perdida num período de 24 horas.

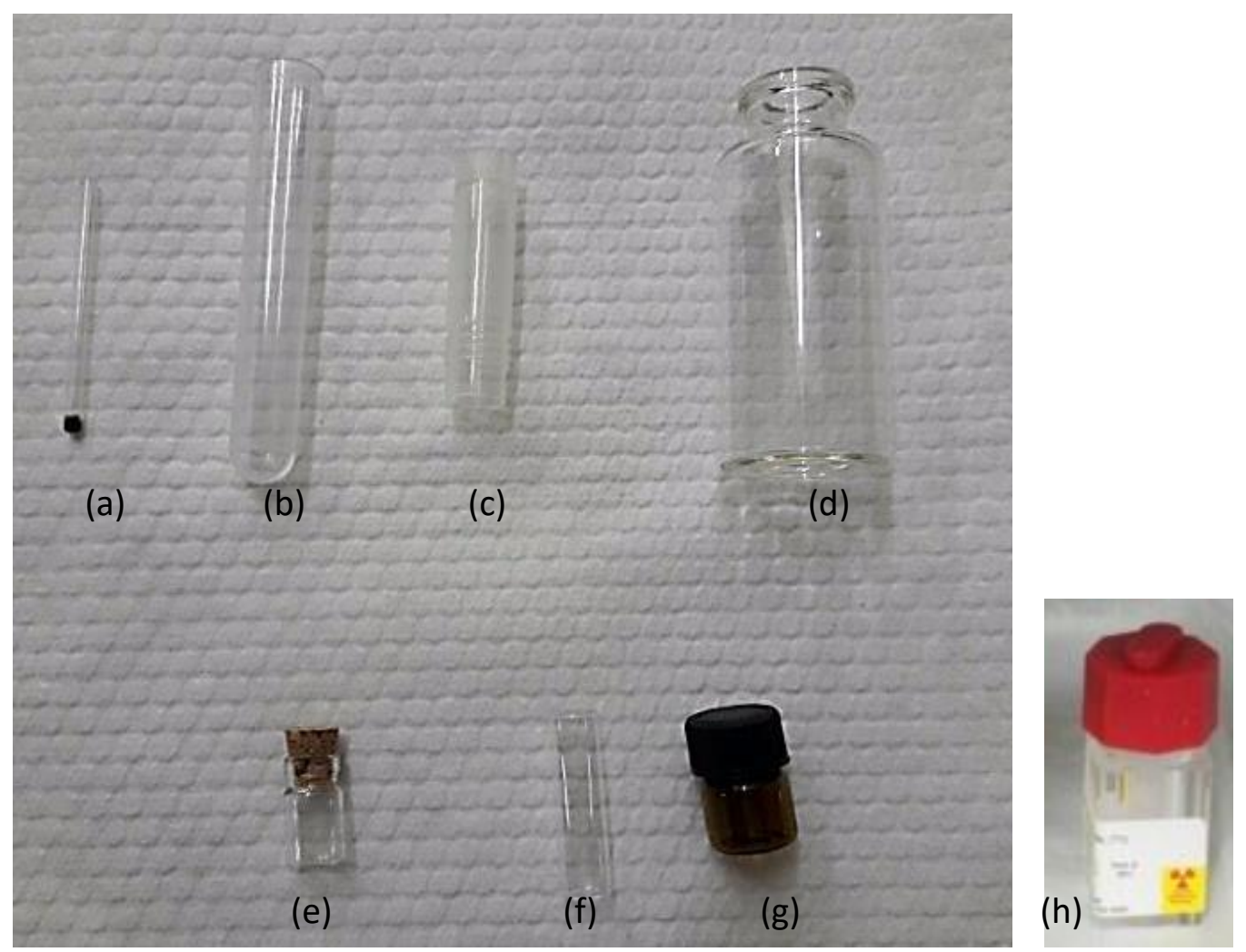

Figura 4: Frascos testados nos experimentos (a) capilar de pirex duplamente vedado com vidro; (b) tubo de ensaio de acrílico - Poli(metilmetacrilato); (c) frasco de polietileno; (d) frasco de vidro tipo penicilina; (e) frasco de vidro tipo pirex; (f) frasco de vidro; (g) frasco de vidro âmbar; (h) frasco utilizado na comercialização do $\mathrm{Na}^{125}$. 
Tabela 8: Eficiência do método 2 variação 1 em diferentes frascos.

\begin{tabular}{|c|c|c|c|c|c|c|c|c|}
\hline & a & b & c & d & e & $f$ & g & $\mathbf{h}$ \\
\hline $\begin{array}{l}\text { Ativ. Total } \\
\text { (mCi) }\end{array}$ & 3,00 & 3,10 & 3,03 & 3,40 & \multirow{2}{*}{$\begin{array}{l}\text { Melhor } \\
\text { frasco }\end{array}$} & 3,25 & 2,90 & 3,00 \\
\hline $\begin{array}{l}\text { Ativ. em } \\
24 \mathrm{~h}(\mathrm{mCi})\end{array}$ & 2,72 & 1,60 & 1,84 & 0,98 & & 1,45 & 2,00 & 1,93 \\
\hline Perda & 0,28 & 1,50 & 1,19 & 2,42 & \multirow{3}{*}{$\begin{array}{c}\text { ver tab } \\
6\end{array}$} & 1,80 & 0,90 & 1,07 \\
\hline $\begin{array}{l}\% \text { de } \\
\text { Perda }\end{array}$ & 9,33 & 48,39 & 39,27 & 71,18 & & 55,38 & 31,03 & 35,67 \\
\hline $\begin{array}{l}\text { Núcleo } 1 \\
(\mathrm{mCi})\end{array}$ & 0,09 & 0,12 & 0,01 & 0,05 & & 0,06 & 0,04 & 0,08 \\
\hline $\begin{array}{c}\text { Núcleo } 2 \\
\text { (mCi) }\end{array}$ & 0,07 & 0,08 & 0,01 & 0,04 & & 0,10 & 0,09 & 0,07 \\
\hline $\begin{array}{l}\text { Núcleo } 3 \\
(\mathrm{mCi})\end{array}$ & 0,04 & 0,06 & 0,01 & 0,07 & & 0,03 & 0,10 & 0,08 \\
\hline $\begin{array}{l}\text { Total } \\
(\mathrm{mCi})\end{array}$ & 0,20 & 0,26 & 0,03 & 0,16 & & 0,19 & 0,23 & 0,23 \\
\hline Desvio & 0,02 & 0,02 & 0,00 & 0,01 & \multirow[b]{2}{*}{$\begin{array}{l}\text { Valor } \\
\text { médio } \\
19,17 \%\end{array}$} & 0,02 & 0,02 & 0,00 \\
\hline $\begin{array}{c}\% \text { de } \\
\text { eficiência }\end{array}$ & 6,67 & 8,39 & 1,06 & 4,71 & & 5,85 & 7,93 & 7,67 \\
\hline
\end{tabular}

Tabela 9: Perda de material, método 2 variação 1 para o frasco (h).

\begin{tabular}{cc}
\hline Horário de medição & Atividade (mCi) \\
\hline $\mathbf{0 9 : 4 5}$ & 3,46 \\
$\mathbf{1 0 : 0 3}$ & 3,43 \\
$\mathbf{1 0 : 5 0}$ & 3,35 \\
$\mathbf{1 1 : 3 4}$ & 3,23 \\
$\mathbf{1 2 : 0 5}$ & 3,10 \\
$\mathbf{1 2 : 5 2}$ & 3,03 \\
$\mathbf{1 3 : 3 9}$ & 2,93 \\
$\mathbf{1 4 : 1 7}$ & 2,75 \\
$\mathbf{1 4 : 5 4}$ & 2,75 \\
$\mathbf{1 5 : 2 7}$ & 2,59 \\
$\mathbf{1 6 : 0 3}$ & 2,48 \\
$\mathbf{1 6 : 3 7}$ & 2,64 \\
$\mathbf{1 7 : 1 3}$ & 2,65 \\
$\mathbf{1 7 : 4 8}$ & 2,41 \\
$\mathbf{1 8 : 2 0}$ & 2,59 \\
$\mathbf{1 8 : 5 7}$ & 2,45 \\
$\mathbf{1 9 : 2 5}$ & 2,67 \\
$\mathbf{2 1 : 0 0}$ & 2,49 \\
$\mathbf{0}: 40$ & 2,28 \\
$\mathbf{1 0 : 1 0}$ & 2,26 \\
\hline perda total (mCi) & 1,20 \\
\% de perda total & $34,68 \%$ \\
\hline
\end{tabular}




\subsubsection{Potencial de Hidrogênio - $\mathrm{pH}$}

O meio básico é indicado para ser utilizado pela a maior parte dos autores e produtores, seguindo a teoria que o meio básico desfavorece o comproporcionamento

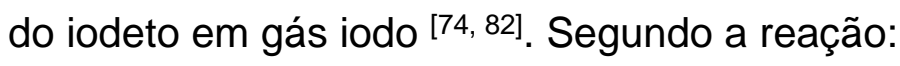

$$
\mathrm{I}_{2}+\mathrm{H}_{2} \mathrm{O} \leftrightarrow \mathrm{H}^{+}+\mathrm{I}^{-}+\mathrm{HIO}
$$

Mas a solução utilizada na reação é de Nal e não l2. Para o Nal, deve-se considerar a seguinte equação:

$$
\mathrm{NaI}+\mathrm{NaOH} \underset{\text { ásico }}{\stackrel{\overleftarrow{\text { ácido }}}{\longrightarrow}} \mathrm{Na}^{+}+\mathrm{I}^{-}+\mathrm{OH}^{-}
$$

Ao observar as reações, conclui-se que ambas podem alterar o equilíbrio final. Portanto, pH ideal do experimento é extremamente relevante (em concordância com

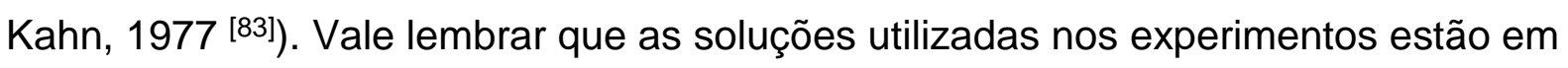
concentrações ínfimas e, de acordo com o princípio da radioquímica, os resultados podem ser imprevisíveis. Além disso, a solução de $\mathrm{Na}^{125}$ I quando se encontra sobre armazenamento pode ser considerada em "equilíbrio". A partir do momento que é utilizada em uma reação que promove o desproporcionamento do Nal e a inclusão de novos íons, o equilíbrio se altera e características antes utilizadas no armazenamento podem não serem as mesmas durante a reação. Para tal, diversas soluções com diferentes $\mathrm{pH}$ foram feitas acrescentando ácido clorídrico e hidróxido de sódio às soluções utilizadas no método 1 e 2. Como investigação inicial, foi utilizado $0,20 \mathrm{mCi}$ de atividade radioativa em cada variação e soluções de diferentes $\mathrm{pH}$ tentando ao máximo a obtenção do mesmo volume final, $200 \mu \mathrm{L}$. O pH foi medido com uma fita de $\mathrm{pH}$, descartada posteriormente como rejeito radioativo. $\mathrm{O}$ resultado está na tabela 10. 
Tabela 10: Ensaio de análise de perda de iodo-125 realizado com diferentes $\mathrm{pH}$.

\begin{tabular}{|c|c|c|c|c|c|}
\hline \multirow{2}{*}{$\mathrm{pH}$} & & \multicolumn{2}{|c|}{ Método 1} & \multicolumn{2}{|c|}{ Método 2 variação 1} \\
\hline & & $\%$ & $\%$ & $\%$ & \\
\hline \multirow{4}{*}{$\mathrm{NaOH}$} & 14 & 3,27 & 4,58 & 5,29 & 3,40 \\
\hline & 12 & 2,00 & 0,90 & 1,84 & 1,20 \\
\hline & 10 & 6,30 & 5,00 & 3,21 & 4,00 \\
\hline & 8,1 & 4,67 & 3,79 & 5,26 & 2,13 \\
\hline \multicolumn{2}{|l|}{ Média } & \multicolumn{2}{|c|}{$3,81 \%$} & \multicolumn{2}{|c|}{$3,29 \%$} \\
\hline \multirow{4}{*}{$\mathrm{HCl}$} & 7 & 3,96 & 2,60 & 3,32 & 2,90 \\
\hline & 4,7 & 0,53 & 1,00 & 0,89 & 2,00 \\
\hline & 3,1 & 1,00 & 0,71 & 1,41 & 1,67 \\
\hline & 1,1 & 3,16 & 2,82 & 4,98 & 4,20 \\
\hline \multicolumn{2}{|l|}{ Média } & \multicolumn{2}{|c|}{$1,97 \%$} & \multicolumn{2}{|c|}{$2,67 \%$} \\
\hline
\end{tabular}

Os resultados sugerem que o meio pode não influenciar o resultado. A maioria dos pesquisadores e todas as fichas técnicas ressaltam a importância de utilizar o meio básico. Porém, algumas publicações recentes começaram a questionar a afirmação. Por exemplo, no artigo "Preparation of the radioactive source core of iodine-125 seed" de Jiaheng et al foi mostrado que a eficiência de fixação diminui conforme o pH aumenta (figura 5) ${ }^{[84]}$.

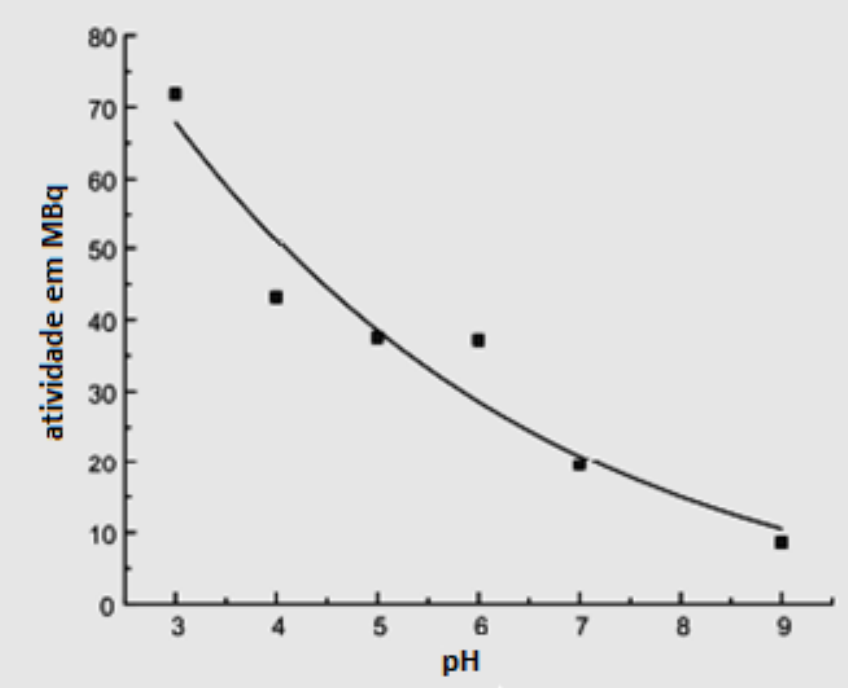

Figura 5: Eficiência de fixação de iodeto no núcleo de prata versus o valor do pH. De acordo com a referência ${ }^{[84]}$. 
Como a solução de $\mathrm{Na}^{125}$ é comercializada em meio básico, deve ser considerada também a competição iônica entre o $\mathrm{OH}^{-}$e o l- com o íon $\mathrm{Ag}^{+}$. Para um experimento segundo o método 2 variação 1 , encontra-se $7,00.10^{6}$ vezes mais átomos de $\mathrm{OH}^{-}$do que $\mathrm{I}^{125-}$.

Como conclusão, fica claro que o $\mathrm{pH}$ em que o experimento é realizado é de extrema importância. Por essa razão, nenhuma suposição foi adotada durante a execução deste trabalho. Foram testados diferentes valores $\mathrm{pH}$ para cada método, desta vez seguindo as mesmas indicações apresentadas no item 4.2 (inclusive 0 volume final). $O$ valor que resultou em maior fixação de material foi o adotado em todos os outros experimentos. Soluções de 0,01, 0,50 e 1,00 M de $\mathrm{NaOH}$ e HCl foram utilizadas para ajustar o $\mathrm{pH}$ para o valor desejado. $\mathrm{O} \mathrm{pH}$ final dos experimentos foi determinado por uma fita indicadora de $\mathrm{pH}$, descartada postriomente como rejeito radioativo. De acordo com os resultados da tabela 11, no método 1, valores altos de $\mathrm{pH}$ resultaram em diminuição na eficiência. Já no método $2,0 \mathrm{pH}$ básico diminuiu a eficiência e o pH ácido ou não alterarou ou piorou o resultado.

Tabela 11: Eficiência das metodologias em diferentes $\mathrm{pH}$.

\begin{tabular}{|c|c|c|c|c|c|c|c|}
\hline & método 1 & \multicolumn{2}{|c|}{ método 2 var. 1} & \multicolumn{2}{|c|}{ método 2 var. 2} & \multicolumn{2}{|c|}{ método 2 var. 3} \\
\hline $\mathrm{pH}$ & $\approx 1$ & \multicolumn{2}{|c|}{$\approx 6$} & \multicolumn{2}{|c|}{$\approx 6,10$} & \multicolumn{2}{|c|}{$\approx 6,20$} \\
\hline $\begin{array}{c}\text { Eficiência } \\
\text { atingida }\end{array}$ & $\begin{array}{c}37,76 \% \pm \\
6,40 \%\end{array}$ & \multicolumn{2}{|c|}{$\begin{array}{c}19,17 \% \pm \\
3,90 \%\end{array}$} & \multicolumn{2}{|c|}{$\begin{array}{c}53,39 \% \pm \\
3,60 \%\end{array}$} & \multicolumn{2}{|c|}{$\begin{array}{c}71,70 \% \pm \\
4,30 \%\end{array}$} \\
\hline $\mathrm{pH}$ & $\approx 9$ & $\approx 1$ & $\approx 9$ & $\approx 1$ & $\approx 9$ & $\approx 1$ & $\approx 9$ \\
\hline $\begin{array}{c}\text { Eficiência } \\
\text { atingida }\end{array}$ & $\begin{array}{c}19,77 \% \pm \\
3,18 \% \\
\end{array}$ & $\begin{array}{c}18,22 \% \pm \\
2,18 \% \\
\end{array}$ & $\begin{array}{c}14,83 \% \pm \\
2,11 \% \\
\end{array}$ & $\begin{array}{c}49,75 \% \pm \\
1,16 \% \\
\end{array}$ & $\begin{array}{c}47,09 \% \pm \\
1,35 \% \\
\end{array}$ & $\begin{array}{c}70,71 \% \pm \\
1,52 \% \\
\end{array}$ & $\begin{array}{c}59,33 \% \pm \\
1,23 \% \\
\end{array}$ \\
\hline
\end{tabular}

\subsubsection{Volume da solução}

$O$ volume em que a reação é realizada também foi estudado. Testes com maior concentração de iodo radioativo apresentaram melhores resultados (tabela 12). Além disso, uma vez que os núcleos são posicionados dentro do frasco, eles se aglomeram no fundo do frasco fazendo com que uma pequena quantidade de solução seja suficiente para a reação (figura 6). Portanto, frasco e volumes pequenos são ideais para o experimento. 

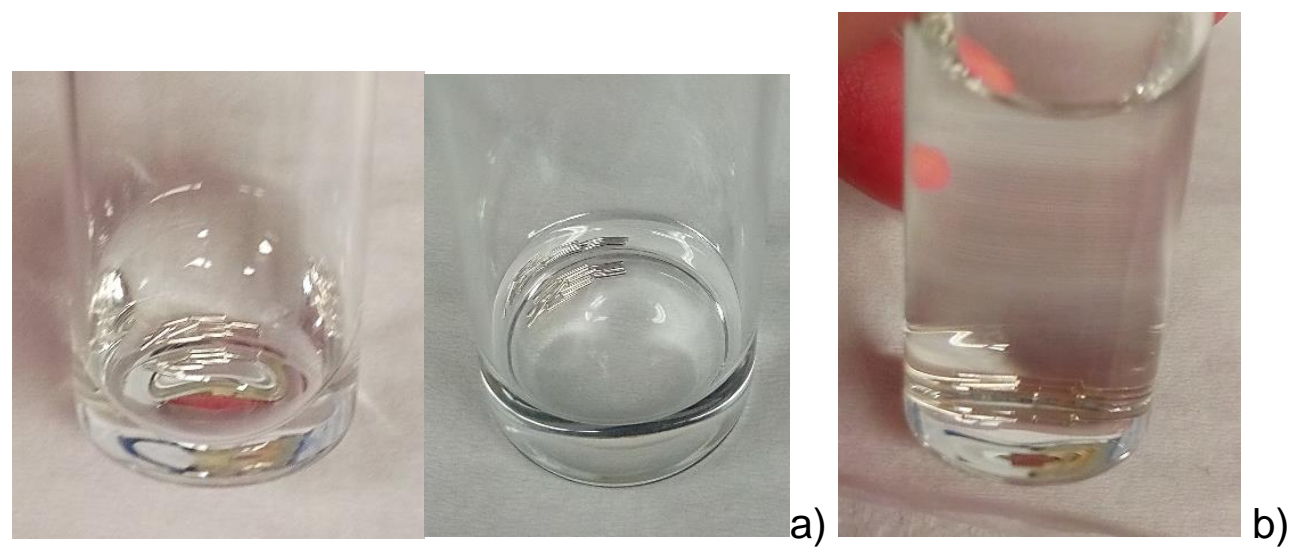

Figura 6: Núcleos de prata em a) $1 \mathrm{~mL}$ de soloção, b) $5 \mathrm{~mL}$ de solução.

Tabela 12: Resultados do método 2 variação 1 realizado com volumes finais diferentes (o volume foi variado com água destilada).

\begin{tabular}{ccc}
\hline Volume final & $\mathbf{1 5 0} \boldsymbol{\mu L}$ & $\mathbf{5 0 0} \boldsymbol{\mu L}$ \\
\hline $\begin{array}{c}\text { Concentração da } \\
\text { sol. radioativa }\end{array}$ & $0,018 \mathrm{mCi} / \mu \mathrm{L}$ & $0,006 \mathrm{mCi} / \mu \mathrm{L}$ \\
Eficiência atingida & $19,17 \% \pm 3,90 \%$ & $13,82 \% \pm 3,77 \%$ \\
\hline
\end{tabular}

\subsubsection{Rejeito Radioativo e segurança}

Parte do iodo radioativo adere na parede do frasco utilizado para 0 experimento, parte não reage permanecendo na solução e parte volatiliza. $O$ rejeito líquido deve ser armazenado em frascos estanques. O rejeito sólido deve ser guardado em pelo menos 3 camadas de sacos bem fechados. O rejeito gasoso deve ser recolhido em um filtro de carvão ativado. Independente da medida aplicada, devese avaliar periodicamente a eficácia de filtragem.

Dentre as formas de rejeito radioativo geradas, o gasoso é o mais perigoso, visto que pode ser facilmente inalado. Uma análise de volatilização do gás iodo foi realizado na capela utilizada nos experimentos. Sachês com carvão ativado foram posicionados em locais de interesse dentro da capela conforme a figura 7. Nenhum vazamento foi detectado. 

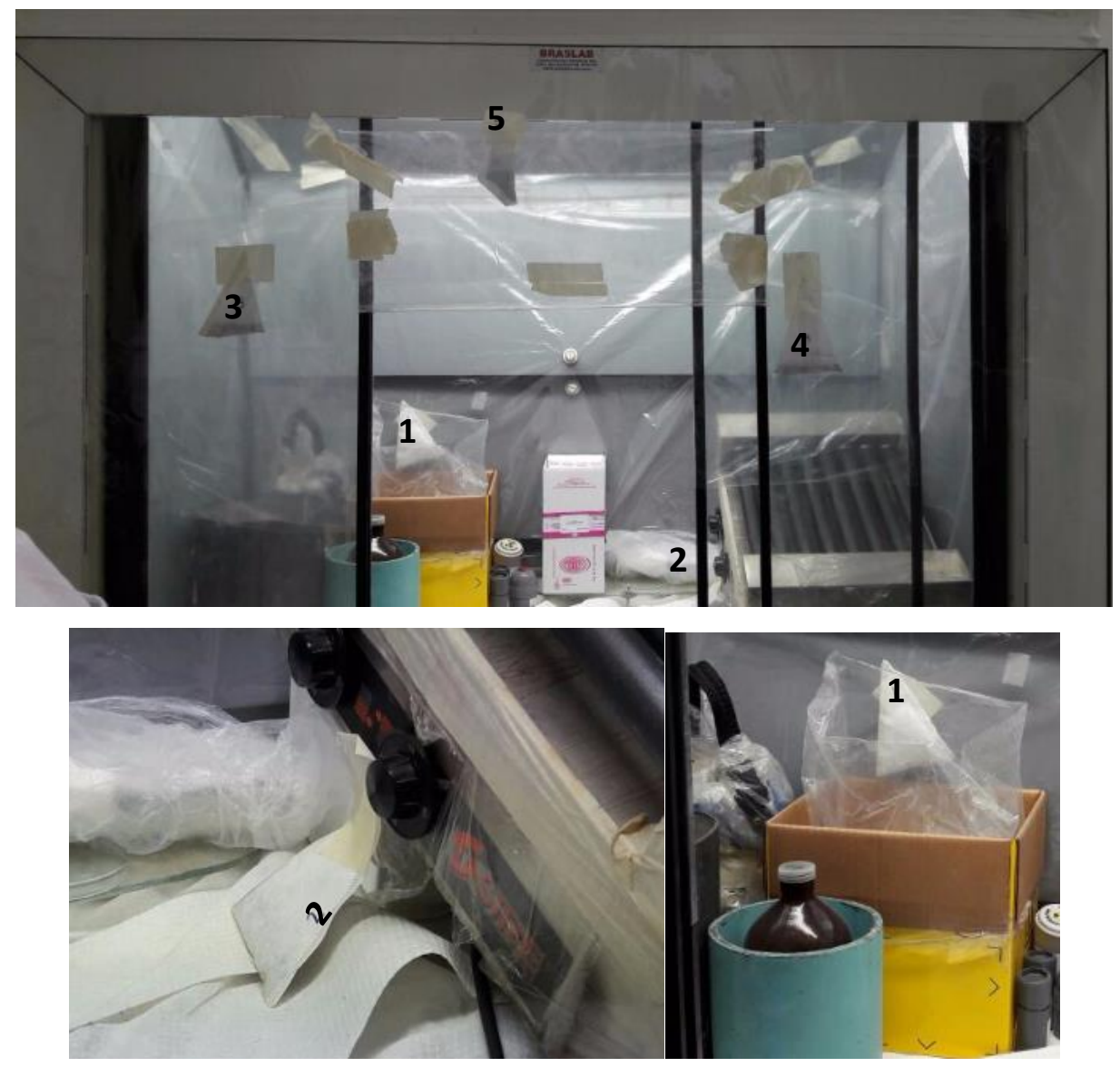

Figura 7: Posição dos sachês com carvão ativado na capela utilizada nos experimentos.

\subsubsection{O fornecedor do iodo}

Durante os anos de 2012-2015 o IPEN adquiriu o $\mathrm{Na}^{125}$ da MS Nordion Canadá. Em 2016, o fornecedor foi alterado para Perkin-Elmer - Estados Unidos. O método 1 , método 2 variação 1 e os testes teóricos foram realizados no período 2012-2015. O método 2 variação 2 e 3 foram investigadas no primeiro semestre de 2016. A validação experimental se completou no segundo semestre de 2015.

Na tentativa de se obter resultados confiáveis, o estudo do $\mathrm{pH}$ e todos os testes finais foram repetidos. Os resultados encontrados para o mesmo método aplicado ao material dos diferentes fornecedores foram completamente diferentes (tabela 13).

Tabela 13: Comparação de metodologias com diferentes fornecedores.

\begin{tabular}{ccccc}
\hline & \multicolumn{2}{c}{ Método 1 } & \multicolumn{2}{c}{ Método 2 Variação 1 } \\
\hline Fornecedor & Ms Nordion & P. Elmer & Ms Nordion & P. Elmer \\
Eficiência & $69,80 \% \pm 2,30 \%$ & $37,76 \% \pm 6,40 \%$ & $57 \% \pm 8,30 \%$ & $19,17 \% \pm 3,90 \%$ \\
\hline
\end{tabular}


Ambas as companhias não oferecem certificados atestando a pureza química, apenas garantem a pureza radioativa. Além disso, nenhum dado sobre produção, purificação e caracterização é oferecido.

\subsection{Análise da superfície da prata}

A Microscopia Eletrônica de Varredura (MEV) é capaz de produzir imagens de alta resolução. As imagens têm aparência tridimensional tornando-se úteis para avaliar a estrutura superficial de uma amostra. A técnica consiste em se utilizar um feixe de elétrons para explorar a superfície da amostra, ponto a ponto, e um detector e software para detecção e interpretação do sinal captado [85].

Não foi possível mensurar mudança de massa após ambos os pré-tratamentos (a massa do núcleo difere na sexta casa decimal). Os núcleos tratados com a solução piranha foram confeccionados minutos antes da análise. Os núcleos de prata tratados com talco, talco e tiossulfato de sódio e somente com tiossulfato de sódio ficaram 2 meses em contato seus respecticvos tratamentos. Todas as amostras foram limpas durante 5 minutos em um limpador ultrassonico com acetona. O procedimento foi repetido com álcool etílico, respectivamente.

As imagens MEV foram realizadas na Washington State University em Pullman-EUA em um microscópio Hitachi S-570. A figura 8 mostra, em diferentes aumentos, a superfície do núcleo de prata sem nenhum tratamento. Note as marcas feitas pela pinça utilizada no manuseio em $8 \mathrm{~b}$ e as marcas de fabricação na 8c. 

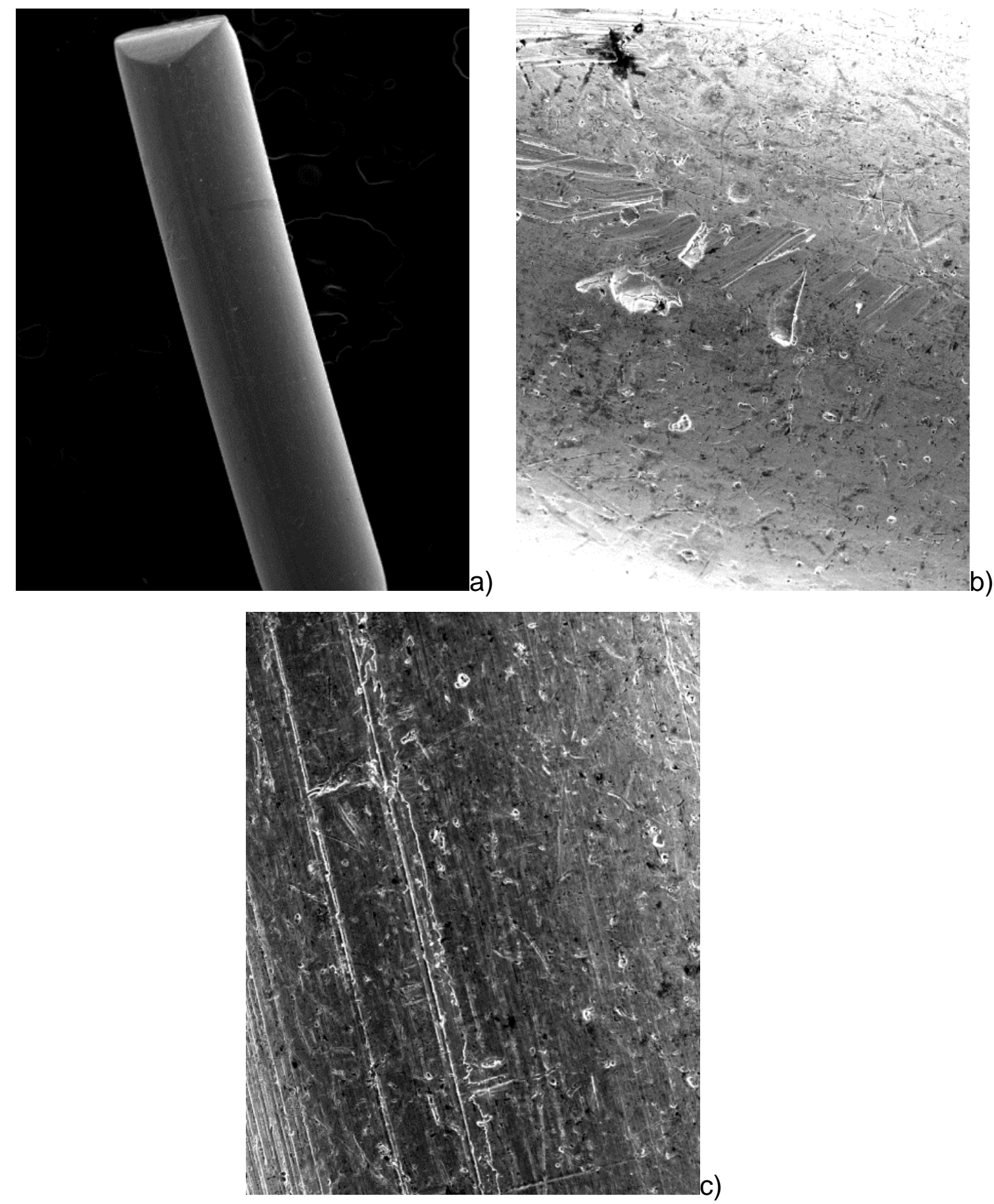

Figura 8: Imagem obtida por MEV do núcleo de prata sem nenhum tratamento. a) imagem com $0,75 \mathrm{~mm}(x 60)$; b) marcas de manuseio (x3000); c) marcas de fabricação (x3000) 
A figura 9 mostra os núcleos de prata tratados com a solução piranha. O tratamento criou porosidade na superfície de maneira homogênea, ou seja, as "nuvelações" tem aproximadamente o mesmo tamanho e aparência.
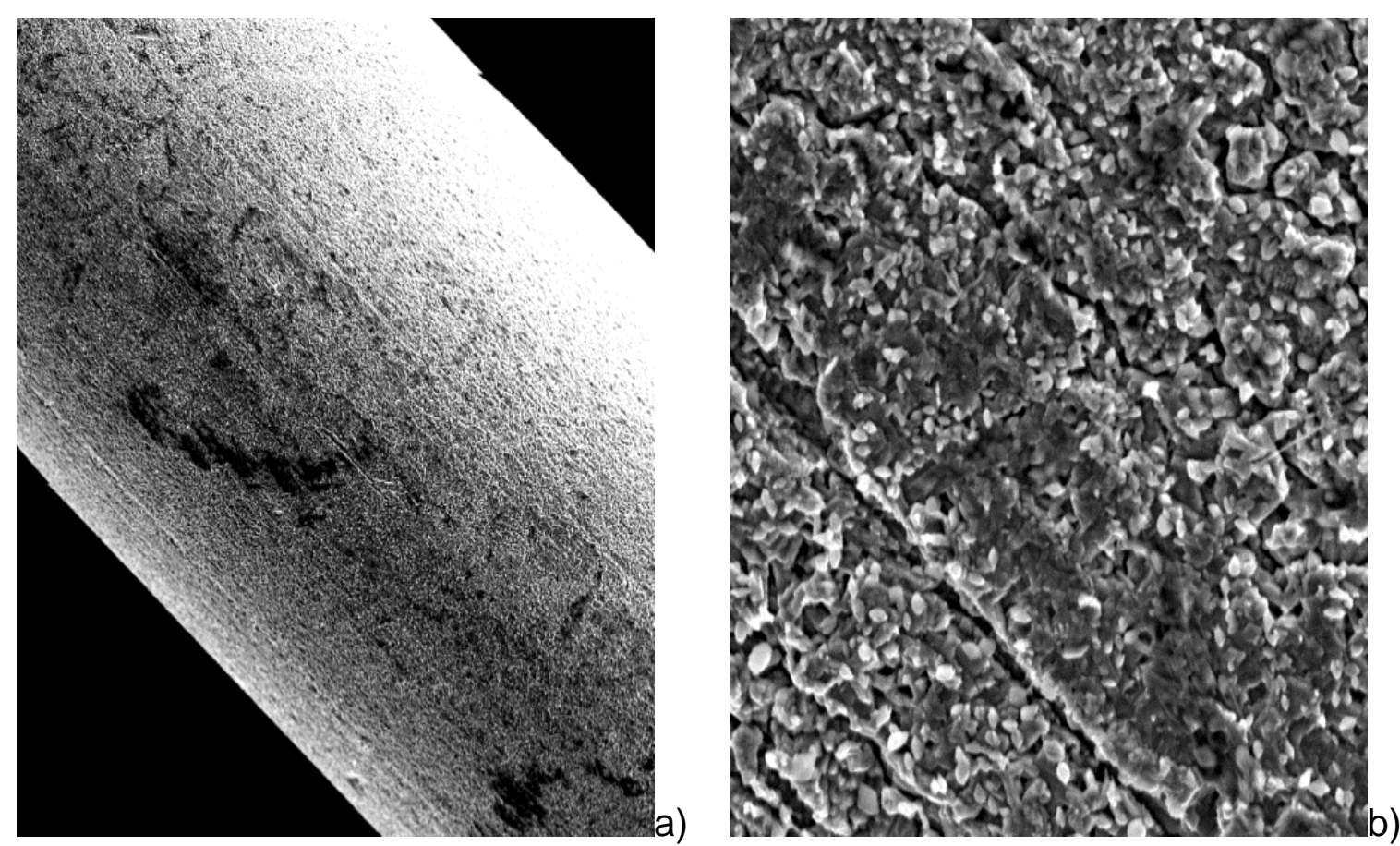

Figura 9: Imagem obtida por MEV do núcleo de prata tratado com solução piranha. a) imagem com $176 \mu \mathrm{m}$ (x300); b) imagem com 13,60 $\mu \mathrm{m}$ mostrando a porosidade da superfície. (x3000)

A figura 10 mostra os núcleos de prata tratados somente com o talco. 0 tratamento criou porosidade na superfície de maneira heterogênea. A figura 10a e 10b mostram pequenos "clusters" de prata sem tratamento. A parte 10c mostra que as "vilosidades" possuem tamanhos e formatos bem diferentes. 

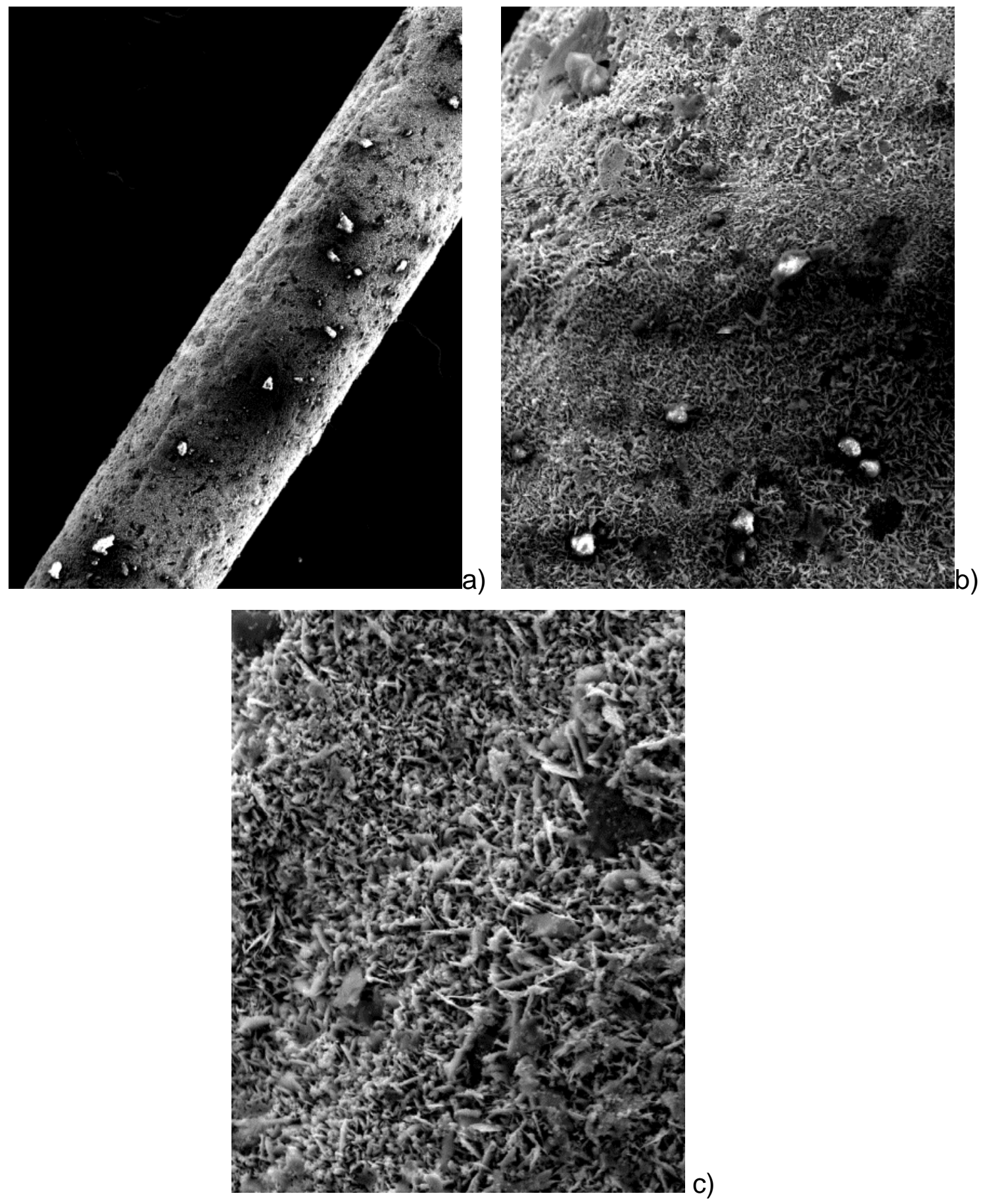

Figura 10: Imagem obtida por MEV do núcleo de prata tratado com talco. a) imagem com 0,50 mm mostrando pedaços que não reagiram (x60); b) zoom da imagem a (x300); c) Vilosidades de tamanhos e formatos diferentes (x3000).

A figura 11 mostra a superfície dos núcleos tratados com talco enriquecido com tiossulfato de sódio. O tratamento criou porosidade na superfície de maneira heterogênea, porém melhor que no tratamento apresentado na figura 10. A figura 11a 
mostra poucos clusters sem tratamento. A parte 11b mostra que as "vilosidades" são mais homogêneas que na figura 10c.
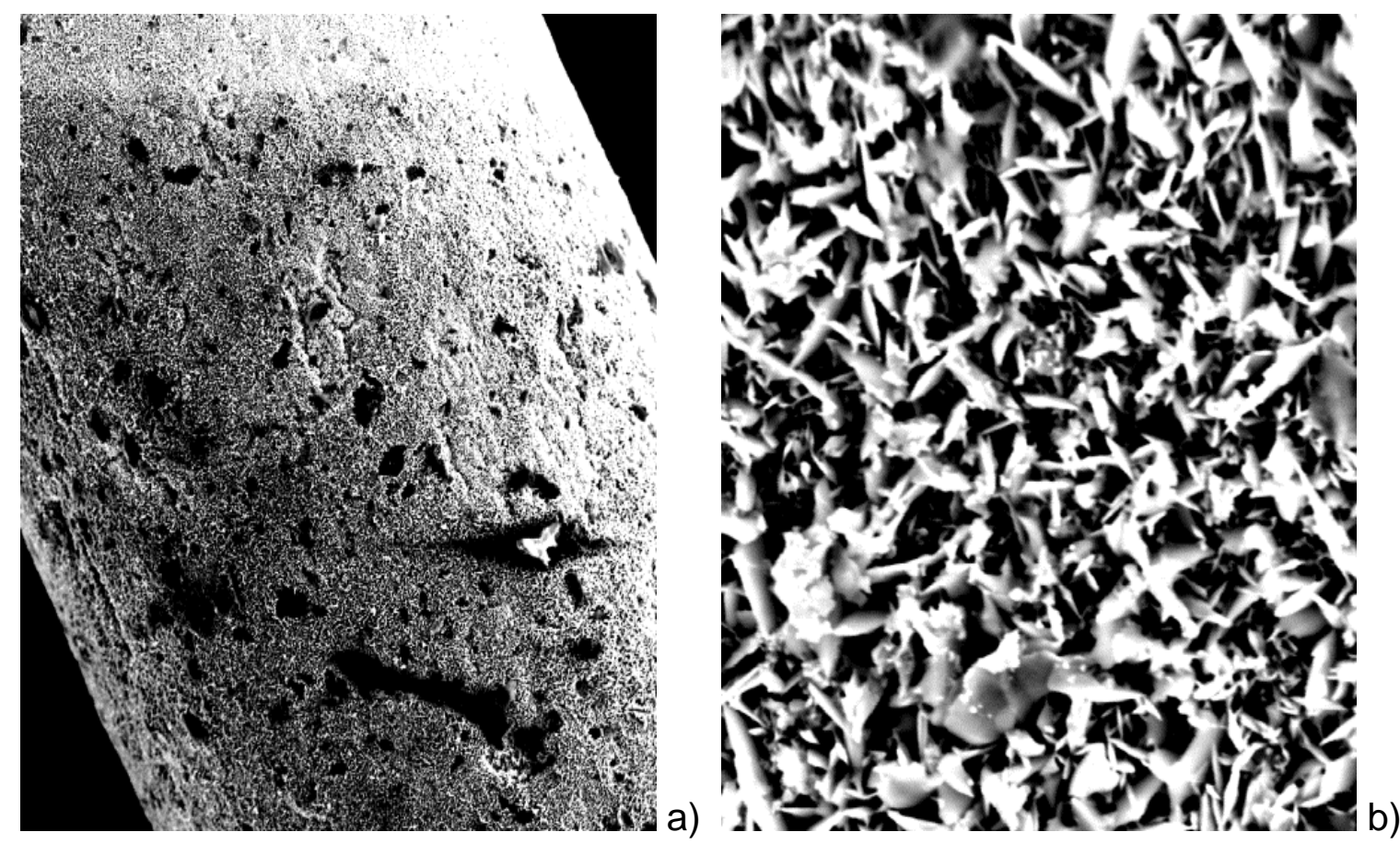

Figura 11: MEV do núcleo de prata tratado com talco enriquecido com tiossulfato de sódio. a) imagem com $150 \mu \mathrm{m}$ mostrando apenas um pedaço que não reagiu (x300); b) Vilosidades aproximadamente homogêneas (x3500).

A figura 12 mostra o núcleo tratado somente com tiossulfato de sódio. É possível identificar placas de tiossulfato na superfície. As placas estão distribuídas desordenadamente. 

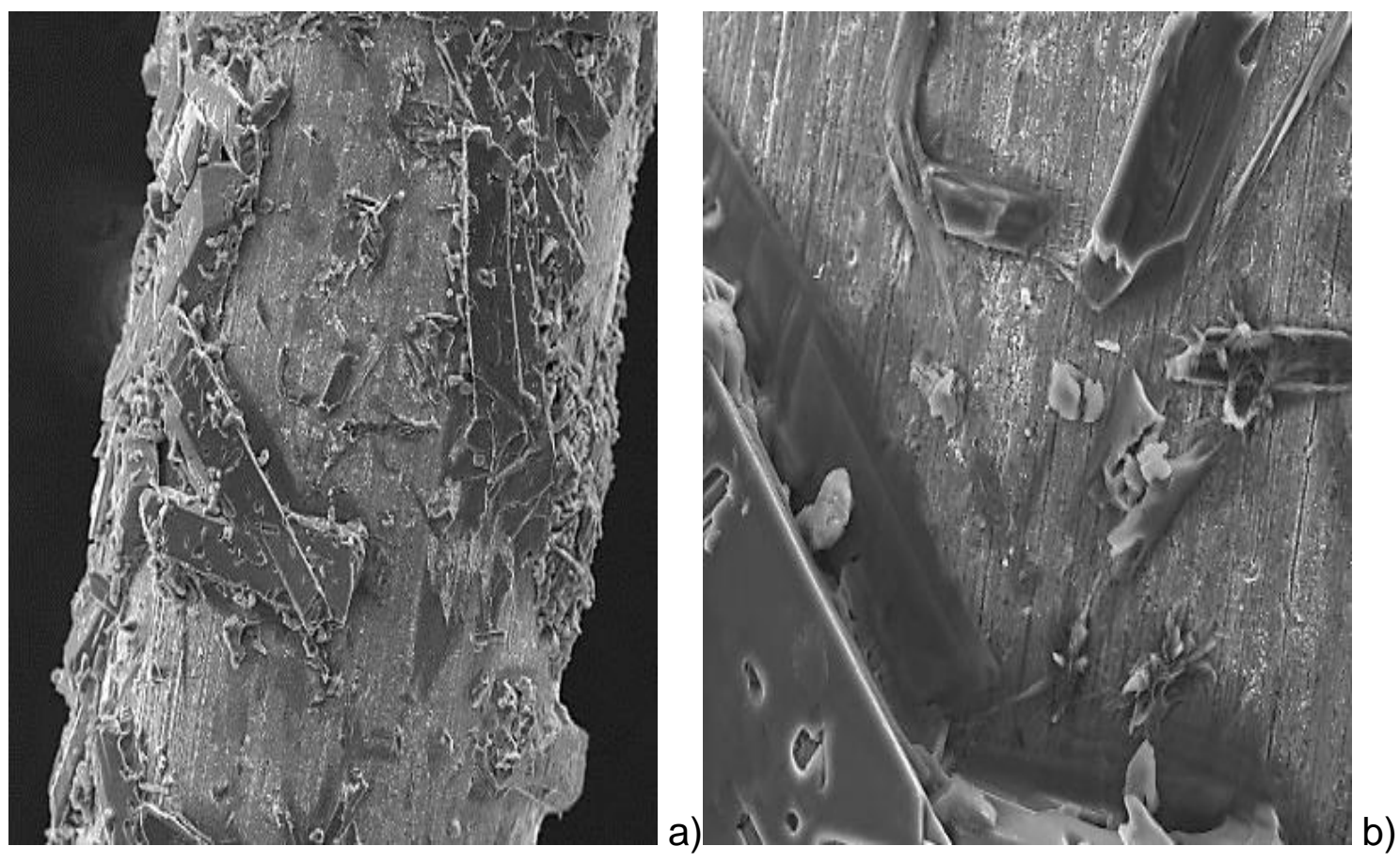

Figura 12: MEV do núcleo de prata tratado com tiossulfato de sódio. a) imagem com $150 \mu \mathrm{m}$ mostrando as placas de tiossulfato (x300); b) Placas vistas em maior aumento $(\times 3500)$.

A análise EDX - Espectroscopia de raios $X$ por dispersão em energia é realizada normalmente junto com o MEV e permite identificar os elementos presentes em uma amostra. Uma fonte de radiação de energia elevada provoca a excitação dos átomos da amostra. Essa energia absorvida permite que elétrons saltem a níveis mais energéticos. Ao retornar ao estado anterior, raios $X$ característicos são gerados $e$ emitidos da amostra. Tais raios possuem um comprimento de onda e uma energia específicos que são característicos de cada elemento. ${ }^{\left[{ }^{86]}\right.} \mathrm{A}$ análise está apresentada na figura 13. A contaminação da amostra por zinco e o crescente aumento da quantidade de enxofre podem ser detectados. É possível perceber que a reação que apresentou maior eficiência (substrato de prata tratado com tiossulfato de sódio) apresentou maior incorporação de enxofre. O núcleo tratado com a solução piranha está presente como referência, pois a fixação do iodeto ocorre diretamente sem íon intermediário. Porém, a superfície incopora enxofre mesmo durante os 5 minutos de tratamento (provavelmente o enxofre é proveniente do ácido sulfúrico). 


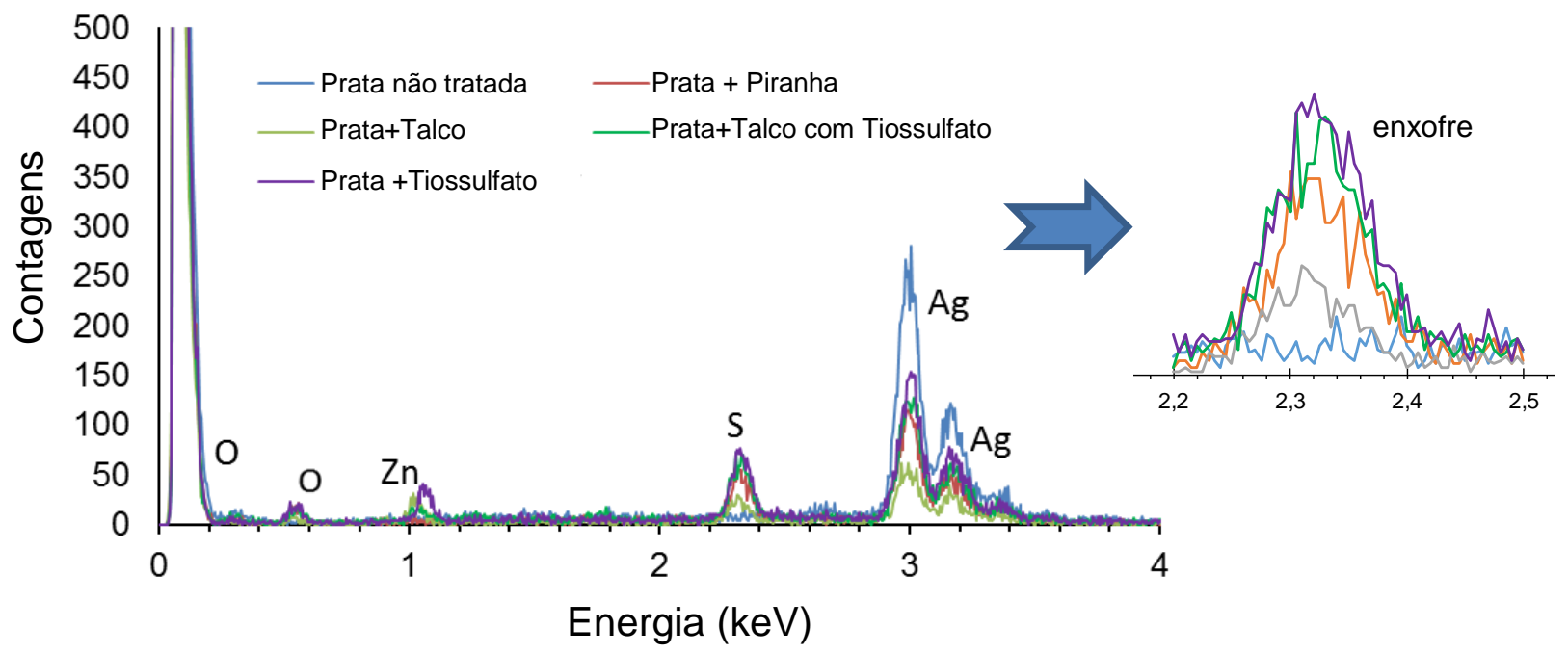

Figura 13: Análise EDX. 


\section{DISCUSSÃO}

Neste trabalho foram apresentadas quatro técnicas para fixação de iodo radioativo em um núcleo de prata utilizado para a fabricação de fontes para tratamento de câncer. O objetivo final foi o desenvolvimento uma metodologia que tenha a maior fixação possível, resultando em um tratamento mais barato e acessível.

A primeira tentativa foi a repetição de trabalhos anteriores, sem sucesso. A necessidade de tratamento prévio na superfície do núcleo de prata ficou comprovada pelo resultado do experimento realizado sem nenhum tratamento, apenas 3,90\% de $\mathrm{I}^{125}$ aderiu na superfície do núcleo de prata. As micrografias apresentadas nas figuras 8-12 mostram a alteração na superfície causada pelo pré-tratamento, e a análise por EDX mostra a forte relação entre eficiência/incorporação de enxofre, causa provável do sucesso das metodologias em aderir o $\mathrm{I}^{-}$.

O primeiro método desenvolvido utilizou a solução piranha para remover a camada superficial deixando a prata livre para ser oxidada e reagir com o iodeto radioativo, atingindo assim o produto final desejado, $\mathrm{Ag}^{125}$. Este processo obteve $37,76 \%$ de eficiência.

O segundo método inspirou-se na observação que talco comum escurece peças de prata. Os núcleos de prata ficaram pretos em aproximadamente uma semana. De acordo com a composição do talco e conhecimentos utilizados por joalheiros e artesãos, foi possível racionalizar a metodologia. A análise foi realiada em três variações: núcleo de prata em contato com somente o talco, 19,17\% de eficiência; núcleo de prata em contato com talco enriquecido com tiossulfato de sódio, $53,39 \%$; e núcleo de prata em contato somente com tiossulfato, $71,70 \%$. Os resultados comprovam que os núcleos de prata aderem com sucesso o íon tiossulfato e a troca com o iodeto ocorre com alto rendimento.

A medição foi realizada pelo método da comparação, pois este método, apesar de imperfeito, considera a perda de material e a atividade final é calculada a partir de medições realizadas no próprio núcleo. $O$ fator de correção para a câmara de ionização não foi utilizado, embora esteja disponível. Este fator foi calculado para sementes prontas e não foi possível a calibração com amostra líquida de $\mathrm{Na}^{125}$.

A reação realizada na presença de luz apresentou resultados piores de fixação (em cerca de 5\%) quando comparada com a ausência de luz. Porém, devido ao 
tamanho diminuto do núcleo e a segurança do processo, optou-se pela manutenção da luz em todos os experimentos.

Os resultados evidenciaram a importância da pureza química dos reagentes utilizados. Por tal razão, substituições normalmente são prejudiciais ao processo. Como o grupo de braquiterapia do IPEN planeja produzir o $\mathrm{Na}^{125}$ I no reator IEA-01 e posteriormente no reator multipropósito, estes dados devem ser considerados na hora que o procedimento de purificação for desenvolvido.

$\mathrm{O} \mathrm{pH}$ da reação, junto com a pureza química, é determinante para o sucesso do experimento. A competição iônica entre $\mathrm{I}^{-} \mathrm{e} \mathrm{OH}^{-}$pode prejudicar a reação como mostram os dados da tabela 11 . O melhor $\mathrm{pH}$ foi escolhido para cada metodologia.

$O$ frasco em que a reação é realizada deve ser de vidro tipo pirex. Frascos de plástico devem ser evitados. O volume final em que a reação é realizada também é importante. Quanto mais concentrada a solução estiver, melhor o resultado. O volume de $150 \mu \mathrm{L}$ cobriu perfeitamente os núcleos e foi facilmente visualizado e coletado pelos equipamentos disponíveis (pipetas e seringas de vidro).

A mudança de fornecedor mostrou-se preocupante devido as grandes diferenças encontradas (tabela 13). Como não é possível realizar análises químicas no material e compará-los, os resultados são dependentes diretos das características do material fornecido. Caso o fornecedor mude novamente, a metodologia deverá sofrer alterações. 


\section{CONCLUSÃO}

Como a incidência do câncer de próstata tem aumentado significativamente nos últimos anos, é de extrema necessidade a criação de tratamentos que sejam eficazes, menos invasivos e que resultem em menos efeitos colaterais. Neste contexto, a radioterapia interna, ou braquiterapia, com sementes de iodo-125 é uma boa opção. Este trabalho está inserido dentro do grupo de produção de fontes para braquiterapia IPEN e teve a finalidade de desenvolver uma metodologia que fixasse o iodo-125 na superfície de um núcleo de prata que será encapsulado em titânio e então posicionado diretamente dentro do câncer.

Dois métodos foram desenvolvidos. A primeira utilizou nitrato de ferro III para oxidar a prata em núcleos pré tratados com a solução piranha. O produto desejável, $\mathrm{Ag}^{125}$ I, é formado após a reação com $\mathrm{Na}^{125}$. Este processo apresentou $37,76 \%$ de eficiência.

O segundo método foi criada partir da observação que talco comum escurece peças de prata. Após um estudo feito na composição do talco e nas possíveis trocas iônicas concluiu-se que há a possibilidade de formação de uma camada de tiossulfato de prata na superfície. Este composto é muito conhecido na área de joalheria e de artesanato. O tiossulfato troca facilmente com iodeto formando produto desejado, iodeto de prata. Então, três variações deste método foram testadas: núcleos de prata em contato com o talco; os núcleos de prata em contato com o talco enriquecido com tiossulfato de sódio; e os núcleos de prata em contato somente com o tiossulfato de sódio. Essa última variação foi a que apresentou a maior eficiência, $71,70 \%$, comprovando a teoria.

Micrografia eletrônica de varredura foi realizada nos núcleos de prata. As imagens geradas possibilitaram a visualização das modificações realizadas na superfície. Análise por EDX mostra o aumento da área superficial e comprova que quanto maior a incorporação de enxofre, maior a fixação de iodo- 125 .

O método da comparação foi utilizado para o cálculo da eficiência neste trabalho, pois ele foi considerado mais próximo da realidade apesar de também ser impreciso.

Outras questões teórico-práticas foram observadas. Por exemplo, o questionamento da pureza química da solução é muito importante, assim como o tipo 
do frasco utilizado. Foram testados diversos frascos presentes no laboratório e chegou-se à conclusão que o melhor é um frasco pequeno de pirex.

A importância da pureza química ficou evidenciada ao observar a mudança de resultados com a alteração do fornecedor. Tudo indica que ambos materiais têm características diferentes e que elas influenciam o resultado em valores muito grandes (mais de 30\% em fixação de diferença). Caso o fornecedor do iodo mude novamente, a metodologia deve ser revista. É fundamental que a equipe de produção de fontes do IPEN produza o iodo-125 no Brasil, para que a metodologia seja padronizada para um material com pureza química conhecida.

A concentração da solução é outra questão fundamental do processo. Quanto mais concentrado, melhor o resultado. $O$ volume escolhido deve permitir a visualizalização e a praticidade operacional. O volume final adotado foi de $150 \mu \mathrm{L}$.

$\mathrm{O} \mathrm{pH}$ é outra característica importante. As condições de manipulação mudam de reação para reação como foi comprovado neste trabalho. Testes determinaram qual o melhor $\mathrm{pH}$ para cada metodologia (tabela 11).

Também foram feitas algumas observações de segurança como o uso de carvão ativado em sachês posicionados em lugares estratégicos dentro da capela (em que os experimentos foram realizados) para detectar vazamentos. Estes testes comprovaram a boa manutenção da capela, já que não foram constatados vazamentos.

Este trabalho é imprescindível para o grupo de produção de sementes de Braquiterapia. Como o iodo-125 é o componente mais custoso da fabricação de semente, quanto maior a eficiência da reação química mais barato o produto final. Assim, ele se tornará disponível para uma parcela maior da população. 


\section{Sugestões de trabalhos futuros}

- Estudo da variação do pH durante a reação química;

- Caracterização da superfície do núcleo de prata por outras técnicas como, por exemplo, XPS - Espectroscopia de fotoelétrons excitados por raios X: estudo em andamento (parceria com a Université Laval - Canadá);

- Comparação dosimétrica entre as metodologias com a finalidade de verificar a relação entre o pré-tratamento e a distribuição da dose radioativa;

- Investigação da relação entre o tipo do frasco e a volatilização. 


\section{BIBLIOGRAFIA}

[1] AMERICAN CANCER SOCIETY. Global Cancer Facts \& Figures. ACS: Atlanta, USA, 2015.

[2] MINISTÉRIO DA SAÚDE. INSTITUTO NACIONAL DO CÂNCER. Atlas On-line de Mortalidade por Câncer. Disponível em: <https://mortalidade.inca.gov.br/MortalidadeWeb/>. Acesso em: 17 out. 2015.

[3] MINISTÉRIO DA SAÚDE. INSTITUTO NACIONAL DE CÂNCER. Incidência de Câncer no Brasil. Disponível em: http://www.inca.gov.br/estimativa/2016/estimativa-2016-v11.pdf> Acesso em: 17 out. 2015.

[4] SALVAJOLI, J.V.; SOUHAMI, L.; FARIA, S.L. Radioterapia em Oncologia. Editora Médica-Científica: São Paulo, SP, 1999.

[5] PODGORSAK, E.B. Radiation Oncology Physics: A Handbook For Teachers And Students. International Atomic Energy Agency: Viena, 2005.

[6] MATTOS, F.R. Estudo e Desenvolvimento de uma Semente de Irídio-192 para Aplicação em Câncer Oftálmico. 2013. Dissertação (Mestrado) - Instituto de Pesquisas Energéticas e Nucleares - IPEN-CNEN/SP, São Paulo.

[7] SCHWARZ, S.; THON, N.; NIKOLAJEK, K.; NIYAZI, M.; TONN, J.-C.; BELKA, C.; KRETH, F.-W. lodine-125 brachytherapy for brain tumours - a review. Radiat Oncol, v. 7, n. 1, p. 30, 2012.

[8] SOUZA, C.D. Comparação entre métodos de fixação do iodo radioativo em substrato de prata para confecção de fontes utilizadas em Braquiterapia. 2012. Dissertação (Mestrado) - Instituto de Pesquisas Energéticas e Nucleares - IPEN-CNEN/SP, São Paulo.

[9] VAN DER NOORDAA, M.E.M.; PENGEL, K.E.; GROEN, E.; VAN WERKHOVEN, E.; RUTGERS, E.J.T.; LOO, C.E.; VOGEL, W.; VRANCKEN PEETERS, M.J.T.F.D. The use of radioactive iodine- 125 seed localization in patients with 
non-palpable breast cancer: A comparison with the radioguided occult lesion localization with $99 \mathrm{~m}$ technetium. Eur J Surg Oncol v. 41, n. 4, p. 553-558, 2015.

[10] GOBARDhAN, P.D.; DJAMIN, R.S.; ROMME, P.J.H.J.; DE WIT, P.E.J.; DE GROOT, H.G.W.; ADRIAENSEN, T.; TURKENBURG, J.L.; VEEN, E.J. The use of iodine seed (I-125) as a marker for the localisation of lung nodules in minimal invasive pulmonary surgery. Eur J Surg Oncol, v. 39, n. 9, p. 945-950, 2013.

[11] STANNARD, C.; MAREE, G.; TOVEY, S.; HUNTER, A.; WETTER, J. lodine-125 brachytherapy in the management of squamous cell carcinoma of the oral cavity and oropharynx. Brachytherapy, v. 13, n. 4, p. 405-412, 2014.

[12] JOYCE, F.; BURCHARTH, F.; HOLM, H.H.; STRØYER, I. Ultrasonically guided percutaneous implantation of iodine-125 seeds in pancreatic carcinoma. Int $\boldsymbol{J}$ Radiat Oncol, v. 19, n. 4, p. 1049-1052, 1990.

[13] Shanghai Institute of Nuclear Research, Wang Yong Xiān, Chunfu Zhang, Yin Duanzhi,. lodine-125 seed medicine for intervention treatment and its preparation. CN Pat. N. 1307907A, 2001.

[14] SOUZA, C.D. Braquiterapia com sementes de lodo-125: manufatura e tratamento. 2009. Trabalho de conclusão (bacharelado - Física médica) Universidade Estadual Paulista, Instituto de Biociências, - Botucatu, São Paulo.

[15] ROSTELATO, M.E.C.M. Estudo e Desenvolvimento de uma nova Metodologia para Confecção de Sementes de lodo-125 para Aplicação em Braquiterapia. 2006. Tese (Doutoramento) - Instituto de Pesquisas Energéticas e Nucleares - IPEN-CNEN/SP, São Paulo.

[16] Hazleton Nuclear Science Corporation, Donald C. Lawrence. Therapeutic metal seed containing within a radioactive isotope disposed on a carrier and method of manufacture. US Pat. n. 3.351.0497, 1967.

[17] David O. Kubiatowicz. Radioactive iodine seed. US Pat. n. 4.323.055, 1982. 
[18] RUSSEL, J. A century of brachytherapy. Nucl News, v. 47, p. 44-46, 2004.

[19] Theragenics Corporation, J. L. Russel Jr. X-Ray-Emitting Interstitial Implants. Us Pat. N. 4.702.228, 1987.

[20] Midi-Physics, J. J. McGovern e J. M. Olynyk. Process for depositing I-125 onto a substrate used to manufacture I-125 sources. US Pat.n. 4.729.903, 1988.

[21] Best Industries, K. Suthanthiran. Device and method for encapsulating radioactive materials. US Pat. n. 4891165 A, 1990.

[22] Best Industries, K. Suthanthiran e R. Lakshman. Pellet for a radioactive seed. US Pat. n. 4.994.013, 1991.

[23] North American Scientific, L. Michael Cutrer. Laser welded brachytherapy source and method of making the same US Pat. n. 5997463 A, 1999.

[24] North American Scientific, L. Michael Cutrer. Radioactive seed with multiple markers and method for using same. US Pat. n. 6638207 B2, 2003.

[25] R. Robertson. Encapsulated low-energy brachytherapy sources. US Pat. n. 6.099.458, 2000.

[26] Charles R. Slater, Thomas O. Bales,. Radioactive therapeutic seed having selective marker configuration Us Pat. N. 7172549 B2, 2000.

[27] China Institute of Atomic Energy, Jin Xiaohai, Wang Yuqing, Zhang Jinrong, Bai Hongsheng, Fan Hongqiang, Jia Bing, Zhang Pinyuan. Process for preparing iodine-125 seeds source carrier bar. CN Pat. N. 00103075, 2000.

[28] China Institute of Atomic Energy, Shan Changqi. Preparation process of source core of iodine-125 granule sealed seed source. CN Pat. N. 01123701, 2001.

[29] Bristol-Myers Squibb Pharma Company, Prahlad R. Singh, Gerald P. Tercho, Jack N. Wentz e Keith R. Olewine,. Radioactive seeds for brachytherapy and a process for making the same Us Pat. N. 6391279 B1, 2002. 
[30] Eurotope Entwicklungsgesellschaft Fur Istopentechnologien Mbh, Jürgen Ziegler, Claudia Müller, Gunnar Mann, André Hess. Medical Radioactive lodine-125 Miniature Radiation Sources And Methods Of Producing The Same. Us Pat. N. 6.485.406, 2002.

[31] MANOLKAR, R.B.; SANE, S.U.; PILLAI, K.T.; MAJALI, M.A. Comparison of methods for preparation of $125 \mathrm{I}$ brachytherapy source cores for the treatment of eye cancer. Appl Radiat Isot, v. 59, n. 2-3, p. 145-150, 2003.

[32] MATHEW, C.; MAJALI, M.A.; BALAKRISHNAN, S.A. A novel approach for the adsorption of iodine-125 on silver wire as matrix for brachytherapy source for the treatment of eye and prostate cancer. Appl Radiat Isot, n. 57, n. 3, p. 359367, 2002.

[33] CIESZYKOWSKA, I.; PIASECKI, A.; MIELCARSKI, M. An approach to the preparation of iodine-125 seed-type sources. Nukleonika, v. 50, n. 1, p. 17-22, 2004.

[34] PUCHALSKA, I.; MIELCARSKI, M. Seed-less iodine-125 ophthalmic applicator. Appl Radiat Isot, v. 58, n. 1, p. 15-20, 2003.

[35] INTERNATIONAL ATOMIC ENERGY AGENCY. Production Techniques and Quality Control of Sealed Radioactive Sources of Palladium-103, lodine125, Iridium-192 and Ytterbium-169 (TECDOC-1512). Viena, 2006.

[36] SAXENA, S.K.; SHARMA, S.D.; DASH, A.; VENKATESH, M. Development of a new design 125I-brachytherapy seed for its application in the treatment of eye and prostate cancer. Appl Radiat Isot, v. 67, n. 7-8, p. 1421-1425, 2009.

[37] China Institute of Atomic Energy, Wang Yun-tao. Technique for preparing coating of iodine-125 sealed seed source silver carrier rod. CN Pat. N. 101397659A, 2007.

[38] Chengdu Yunke Pharmaceutical Co, Zhou Xiaolong, Zeng Xiaolin, Li Wei, Li Mingqi, Wang Bangjin, Cheng Zuoyong, Zhong Jihong, Chen Zhen, Chen 
Yahong, Gao Hongwei. Method of preparing iodine-125 sealing seed source core. CN Pat. N. 101401944B, 2008.

[39] Biological Pharmaceutical og Tianjin Teesside Co, Yan Kun Seoul,. Preparation method of therapy used iodine-125 sealed seed source core. CN Pat. N. $1246042 \mathrm{C}, 2004$.

[40] Yan Kun Seoul,. Method for preparing iodine-125 sealed seed source core. CN Pat. N. 201310444386, 2015.

[41] SAXENA, S.K.; KUMAR, Y.; PILLAI, K.T.; DASH, A. Development of a $125 \mathrm{I}$ source for its application in bone densitometry. Appl Radiat Isot, v. 70, n. 3, p. 470-477, 2012.

[42] GONÇALVES, R.G.F.; PINHEIRO, M.V.B.; LACERDA, R.G.; FERLAUTO, A.S.; LADEIRA, L.O.; KRAMBROCK, K.; LEAL, A.S.; VIANA, G.A.; MARQUES, F.C. New material for low-dose brachytherapy seeds: Xe-doped amorphous carbon films with post-growth neutron activated 125I. Appl Radiat Isot, v. 69, n. 1, p. 118-121, 2011.

[43] Korea Atomic Energy Research Institute, Kang Hyuk Choi, Kwang Jae Son, JinHee Lee, Sung-Soo Nam, Sun Ju Choi, . Method of preparing iodine seed for treating eye disease or cancer, and iodine seed prepared thereby. US Pat. N. 20130302244A1, 2012.

[44] LEE, J.H.; CHOI, K.H.; YU, K.H. Surface treatments of silver rods with enhanced iodide adsorption for I-125 brachytherapy seeds. Appl Radiat Isot, v. 85, p. 96100, 2014.

[45] ECKERT \& ZIEGLeR BEBIG. IsoSeed® I-125. Alemanha, 2015.(Catálogo Comercial)

[46] ECKERT \& Zieglen BEBIG. AnchorSeed® I-125. Alemanha, 2015.(Catálogo Comercial) 
[47] HEINTZ, B.H.; WALLACE, R.E.; HEVEZI, J.M. Comparison of I-125 sources used for permanent interstitial implants. Med Phys, v. 28, n. 4, p. 671-682, 2001.

[48] BEST INDUSTRIES. Radioactive Seeds. EUA, 2015.(Catálogo Comercial)

[49] BARD - SourceTeCH MedicAl. Physics of BrachySource. EUA, 2015.(Catálogo Comercial)

[50] FEHER, A. Desenvolvimento de Procedimento Utilizando Processo de Soldagem Plasma para Confecção de Sementes de 125I. 2006. Dissertação (Mestrado) - Instituto de Pesquisas Energéticas e Nucleares - IPEN-CNEN/SP, São Paulo.

[51] FEHER, A. Estudo e desenvolvimento de um sistema de soldagem a laser Nd:YAG para produção de sementes de iodo-125 utilizadas em braquiterapia. 2014. Tese (Doutoramento) - Instituto de Pesquisas Energéticas e Nucleares - IPEN-CNEN/SP, São Paulo.

[52] ZEITUNI, C.A. Dosimetria de Fontes de lodo-125 Aplicadas em Braquiterapia. 2008. Tese (Doutoramento) - Instituto de Pesquisas Energéticas e Nucleares - IPEN-CNEN/SP, São Paulo.

[53] MOURA, E.S. Estudo e levantamento de parâmetros para dosimetria de fontes de iodo-125 aplicadas em braquiterapia. 2011. Dissertação (Mestrado) - Instituto de Pesquisas Energéticas e Nucleares - IPEN-CNEN/SP, São Paulo.

[54] NATH, R., ANDERSON, L.L., LUXTON, G., WEAVER, K.A., WILLIAMSON,J.F., MEIGOONI, A.S. Dosimetry of interstitial brachytherapy sources: recommendations of the AAPM Radiation Therapy Committee (Task Group No. 43). Med Phys, v. 22, p. 209-234, 2005.

[55] MOURA, J.A. Estudo e desenvolvimento de metodologia para controle de qualidade em processo de produção de fontes seladas de lodo-125 para aplicação em braquiterapia. 2009. Dissertação (Mestrado) - Instituto de Pesquisas Energéticas e Nucleares, - IPEN-CNEN/SP, São Paulo. 
[56] INTERNATIONAL STANDARD ORGANIZATION. Radiation protection - sealed radioactive sources - leakage test methods. (ISO - 9978). 1992.

[57] MOURA, J.A. Desenvolvimento e Construção de Sistema Automatizado para Controle de Qualidade na Produção de Sementes de lodo-125. 2015. Tese (Doutoramento) - Instituto de Pesquisas Energéticas e Nucleares, - IPENCNEN/SP, São Paulo.

[58] SOMESSARI, S.L. Automação do processo de soldagem a laser (Nd:YAG) para confecção das sementes de iodo-125 utilizadas em braquiterapia. 2010. Dissertação (Mestrado) - Instituto de Pesquisas Energéticas e Nucleares, - IPEN-CNEN/SP, São Paulo.

[59] COSTA, O.L. Estudo e desenvolvimento de uma nova metodologia de produção de iodo-125 a partir de xenônio-124 pelo método de ativação neutrônica. 2015. Tese (Doutoramento) - Instituto de Pesquisas Energéticas e Nucleares - IPEN-CNEN/SP, São Paulo.

[60] RODRIGUES, B.T. Estudo e desenvolvimento de metodologia para fixação de iodo radioativo em substrato polimérico para confecção de fontes utilizadas em braquiterapia. 2015. Dissertação (Mestrado) - Instituto de Pesquisas Energéticas e Nucleares, - IPEN-CNEN/SP, São Paulo.

[61] PELEIAS JR., F.S. Desenvolvimento da metodologia para síntese do poli(ácido lático-co-ácido glicólico) para utilização na produção de fontes radioativas. 2013. Dissertação (Mestrado) - Instituto de Pesquisas Energéticas e Nucleares, - IPEN-CNEN/SP, São Paulo.

[62] ORCHEL, A.; JELONEK, K.; KASPERCZYK, J.; DOBRZYNSKI, P.; MARCINKOWSKI, A.; PAMULA, E.; ORCHEL, J.; BIELECKI, I.; KULCZYCKA, A. The Influence of Chain Microstructure of Biodegradable Copolyesters Obtained with Low-Toxic Zirconium Initiator to In Vitro Biocompatibility. BioMed Research International, v. 2013, n. 176946, 2013. 
[63] WISNIAK, J. The history of iodine from discovery to commodity. Indian Journal of Chemical Technology, v. 8, n. 6, p. 518-526, 2001.

[64] ABRAHAM, G.E. The history of iodine in medicine. Part 1: From Discovery to Essentiality. The Original Internist, v. 13, n. 1, p. 29-36, 2006.

[65] The National Academies Press. NATIONAL RESEARCH COUNCIL. Health Implications of Perchlorate Ingestion. Washington, DC, 2005.

[66] ZIMMERMANN, M.B.; JOOSTE, P.L.; PANDAV, C.S. lodine-deficiency disorders. Lancet, v. 372, n. 9645, p. 1251-1262, 2008.

[67] ROYAL CHEMICAL SOCIETY. lodine. Disponível em: <http://www.rsc.org/periodic-table/element/53/iodine> Acesso em: 19 jan. 2016.

[68] LEVER, A.B.P. Lewis structures and the octet rule. An automatic procedure for writing canonical forms. Journal of Chemical Education, v. 49, n. 12, p. 819, 1972.

[69] FARRELL, N. Uses of Inorganic Chemistry in Medicine. Royal Society of Chemistry: Cambridge, 1999.

[70] UNITED STATES DEPARTMENT OF ENERGY. NATIONAL NUCLEAR DATA CENTER. Isotopes of the Element lodine. Disponível em: <http://www.nndc.bnl.gov>. Acesso em: 17 fev. 2016.

[71] INTERNATIONAL ATOMIC ENERGY AGENCY. IAEA-TECDOC-1340 - Manual for reactor produced radioisotopes. Disponível em: <http://wwwpub.iaea.org/MTCD/publications/PDF/te_1340_web.pdf> Acesso em: 15 mar. 2016.

[72] KAPLAN, I. Física nuclear. Vol. 2. Guanabara Dois: Rio de Janeiro, RJ, 1978.

[73] NEEB, K.H. The Radiochemistry of Nuclear Power Plants with Light Water Reactors. Walter de Gruyter: Berlin, 1997. 
[74] MELLOR, J.W. A comprehensive treatise on inorganic and theoretical chemistry. Longmans, Green and CO: Londres, 1965.

[75] LIDE, D.R. CRC Handbook of Chemistry and Physics: a Ready-Reference Book of Chemistry and Physical Data. 90 ed. CRC Press: 2009.

[76] MIESSLER, G.L.; FISCHER, P.J.; TARR, D.A. Inorganic Chemistry. Prentice Hall: EUA, 2013.

[77] GOLLBERG, J. The Art \& Craft of Making Jewelry: A Complete Guide to Essential Techniques. Lark Books NC: 2006.

[78] LEE, Y.J.; BENSON, L.B.; O'HARA, R.O. Production and Application of Thiosulfate in Lime-Based Wet FDG. Disponível em: <https://web.anl.gov/PCS/acsfuel/preprint\%20archive/Files/35_4_WASHINGT ON\%20DC_08-90_1392.pdf> Acesso em: 17 out. 2016.

[79] HUGHES, R.; ROWE, M. The Colouring, Bronzing and Patination of Metals. Crafts Council: EUA, 1982.

[80] YU, H.; LIU, L.; WANG, X.; WANG, P.; YU, J.; WANG, Y. The dependence of photocatalytic activity and photoinduced self-stability of photosensitive Agl nanoparticles. Dalton Trans, v. 41, n. 34, p. 10405-10411, 2012.

[81] KENNEDY, J.A.; BESSES, G.S. Comparison of Adsorption of lodine-131Thyroxine to Glass and Plastic Containers. J Nucl Med, v.8, p. 226-228, 1967.

[82] POMEROY, R.; KIRSCHMAN, H.D. The Solubility of Sodium lodide in Sodium Hydroxide Solutions at 20. $\mathbf{J ~ A m ~ C h e m ~ S o c , ~ v . ~ 6 6 , ~ n . ~ 2 , ~ p . ~ 1 7 8 - 1 7 9 , ~} 1944$.

[83] KAHN, M.; KLEINBERG, J. Radiochemistry of lodine. SUBCOMMITTEE ON RADIOCHEMISTRY OF NATIONAL ACADEMY OF SCIENCES-NATIONAL RESEARCH COUNCIL. Technical Information Center, Energy Research and Development Administration: Tennessee (EUA), 1977. 
[84] JIAHENG, H.E.; JIANG, L.; XINGLIANG, L.; WENBIN, Z.; JING, W.; ZONGPING, M.; YUAN, J. Preparation of the radioactive source core of iodine-125 seed. Nucl Sci Tech, v. 20, n. 4, p. 231-234, 2009.

[85] OATLEY, C.W.; NIXON, W.C.; PEASE, R.F.W., Scanning Electron Microscopy, in Advances in Electronics and Electron Physics, L. Marton, Editor 1966, Academic Press. p. 181-247.

[86] KIRKBRIDE, K.P. Analytical Techniques: Spectroscopic Techniques. Elsevier: Oxford, 2000. 